\title{
"Fidelidade Aliancista": as alianças eleitorais nas eleições majoritárias estaduais e o caso do PSB
}

Roberta Carnelos Resende

Sara Epitácio

\section{Introdução}

A utilização de um partido como unidade de análise consiste em um desafio significativo ao pesquisador. Dentre estes, destacam-se a complexidade da estrutura organizacional interna, a dinâmica intra e interpartidária, e o papel desempenhado pelas lideranças e demais filiados nas ações do partido. Tais desafios são potencializados quando se busca analisar a trajetória partidária à luz da participação do partido em arranjos coligacionistas, pois esta ação envolve no mínimo dois agentes (organizações) que, por sua vez, estão sujeitos a variações contextuais como a ampliação da competição política e a alternância ou permanência de blocos aliancistas, além dos aspectos legais advindos de definições normativas que alteram de forma exógena a dinâmica das coligações. Entretanto, analisar o curso coligacional de um partido pode oferecer um importante atalho para a compreensão do comportamento e desenvolvimento eleitoral do mesmo.

A escolha pelo Partido Socialista Brasileiro (PSB) se justifica em virtude da longevidade e de seu crescimento eleitoral nas últimas eleições. Ao contrário dos inúmeros estudos direcionados a análise da atuação do Partido dos Trabalhadores (PT), partido com quem formou importantes e duradouras alianças ${ }^{1}$, o PSB não tem sido objeto de análise, carecendo de estudos que possam compreender como um partido, pouco expressivo eleitoralmente nas décadas de 1980 e meados de 1990, conseguiu ampliar sua capilaridade e conquistar importantes resultados eleitorais. Acredita-se que a análise das suas alianças eleitorais possa fornecer algumas respostas.

Ao mapear a discussão sobre coligações partidária no país na nova democracia, que nos últimos 20 anos têm se tornado uma constante em encontros, produções acadêmicas e

\footnotetext{
${ }^{1}$ Embora alianças e coligações venham sendo utilizadas como sinônimo, optou-se, em função da forma pela qual o objeto será analisado, por utilizar o termo aliança para se referir aos pares (aliança entre A e B, entre A e C, etc.), e coligação para o conjunto dos partidos aliados $(\mathrm{A}+\mathrm{B}+\mathrm{C})$.
} 
publicações², é possível identificar duas dimensões principais de análise, que coincidem e ratificam a importância do trabalho pioneiro de Soares (1964): "ideológica e pragmática". Na primeira, as coligações são percebidas como instrumento de atalho utilizado pelos partidos, que se encontram próximos no espectro ideológico esquerda-direita, para a ampliação das chances de sucesso eleitoral. Quanto à segunda, os competidores em potencial buscam maximizar os votos através de alianças indiscriminadas.

As análises das coligações na nova democracia têm apontado para o aumento das coligações inconsistentes ideologicamente ${ }^{3}$ em detrimento das consistentes (Krause e Godoi, 2010; Carreirão e Nascimento, 2010; Machado e Miguel, 2010). Em se tratando dos resultados eleitorais, Krause e Godoi (2010) constataram que as candidaturas com alianças foram mais bem-sucedidas do que as isoladas, assim como as coligações inconsistentes em termos ideológicos foram mais vitoriosas. Tal mudança de perfil ganhou relevo após as eleições de 1994, momento em que o sistema eleitoral sinalizou para um equilíbrio na competição política ${ }^{4}$ Logo, se não há ganhos eleitorais em alianças consistentes ideologicamente, não haveria razões para fazê-las, tendo em vista o objetivo partidário downsiano de ganhar eleições.

Apesar da relevância dos estudos atuais, o retorno aos trabalhos inaugurais sobre coligações constitui-se de fundamental importância para a compreensão dos argumentos deste trabalho, assim como para a reflexão sobre as ferramentas necessárias ao seu aprimoramento teórico e metodológico. A análise das alianças com base na perspectiva de Gláucio Soares - resistência ideológica e esforço mínimo - não apenas faz sentido para entender a democracia de 1945-1964, mas, conforme a observação da produção acadêmica desta agenda nas últimas décadas, constitui-se em peça-chave para os estudos atuais. Porém, uma coligação pode ser ideológica e ao mesmo tempo pragmática, a depender da conjuntura política, das regras eleitorais, do grau de institucionalização da organização

\footnotetext{
${ }^{2}$ Os estudos recentes em torno desta agenda de pesquisa têm se dedicado, sobremaneira, às análises dos dados eleitorais, e atualmente encontra-se disponível um mapeamento amplo sobre os padrões coligacionais das eleições proporcionais e majoritárias do país (Krause, Dantas e Miguel, 2010; Krause e Schmitt, 2005; Cadernos Adenauer, 2013)

3 A classificação mais recorrente nestes estudos, com pequenas diferenças quanto à nomenclatura, tem abordado a consistência das alianças em termos ideológicos da seguinte maneira: consistentes - com partidos do mesmo espectro ideológico, semiconsistentes - entre partidos de centro e outros de um dos polos, e inconsistentes - coligações variadas, mas que contenham partidos de polos opostos. Ver Schmitt (1999), Krause e Godoi (2010), Dantas (2007), Carreirão (2006).

${ }^{4}$ A partir das eleições de 1994, a competição política para Presidência da República passou a ser estruturada em torno de dois blocos representados pelo PT e PSDB. Esse elemento sinaliza para uma consolidação do sistema (Melo e Camara, 2012).
} 
partidária, e dos objetivos partidários, ou seja, tais dimensões não são mutuamente excludentes.

Soares (1973) constata que as alianças se repetem de uma eleição para outra, no sentido de que um partido que se coligou em um determinado estado, tende a fazê-lo novamente nas eleições seguintes, ao invés de preferir a candidatura isolada. Tal afirmação somada à observação das configurações aliancistas do PSB nas eleições majoritárias estaduais, forneceu instrumentos para pensar se as alianças eleitorais, quando analisadas em pares, e não de maneira agregada, caminho pelo qual a maioria dos estudos têm optado, seriam orientadas por laços de fidelidade entre os partidos. Tais laços são aqui chamados de fidelidade aliancista, entendida como as alianças que se repetem de uma eleição para outra em um determinado espaço e nível eleitoral. Esta abordagem pode ser uma forma mais flexível de analisar os arranjos coligacionais e, porque não, complementar aos critérios ideológicos, que, além de embaraçosos no momento da classificação partidária, em virtude, principalmente, da realidade política atual, já não possuem o mesmo poder explicativo de até meados da década de 1990. Além do mais, manter-se fiel pode ser também uma estratégia para maximizar os ganhos eleitorais nos contextos locais.

Dito isto, o objetivo principal deste trabalho é identificar os perfis de alianças realizadas pelo PSB nas eleições para governador de 1990 a $2014^{5}$. Pretende-se responder às seguintes questões: Quais são os parceiros preferenciais do PSB? Estes pertencem ao mesmo espectro ideológico? O partido opera com uma lógica aliancista particular em cada estado? Parte-se da hipótese de que os laços de fidelidade e lealdade entre os partidos caracterizam as alianças nas eleições para governador. Desse modo, este capítulo está organizado em duas partes principais: a discussão dos trabalhos inaugurais sobre coligações no Brasil, e suas contribuições teórico-metodológicas; e análise das alianças realizadas pelo PSB.

\section{Os estudos pioneiros sobre coligações e suas contribuições teórico-metodológicas}

As alianças partidárias passaram a fazer parte da realidade brasileira durante a democracia de 1945-19646 , sendo centrais para a organização da competição política partidária naquele

\footnotetext{
${ }^{5}$ O PSB participou das eleições para Governador em 1986 no RJ (candidatura isolada), em AL (cabeça de chapa da coligação PSB, PDT, PT, PCB, PL), no CE (coligado ao PT) e AM (cabeça de chapa da coligação PSB, PDC, PDT, PCdoB, PTR, PPB), todas sem sucesso eleitoral. A opção por não trabalhar com os dados de 1986 se deve a dois motivos: a) o PSB foi refundado em 1985, mas conquistou o registro provisório junto ao TSE apenas em 1987; b) os novos partidos não eram institucionalizados e consequentemente não possuíam uma estrutura nacionalizada capaz de competir com o PMDB, herdeiro do MDB, e o PFL, herdeiro político da Arena (Fleischer,2007).O bipartidarismo nestas eleições pode ser observado através dos resultados, com o PMDB elegendo 22 e o PFL 1, do total de 23 governadores.

${ }^{6}$ As eleições e o sistema eleitoral brasileiro neste período foram regulamentados pela Lei Eleitoral de 1945 e pela Constituição Federal de 1946. Os candidatos deveriam ter filiação partidária, podendo ser pelo próprio partido ou por aliança eleitoral. Com 9 alianças para a Câmara dos Deputados e 4 para as disputas das Assembleias Estaduais, as eleições
} 
momento, e ainda hoje. No entanto, até o estudo de Gláucio Soares (1964), não havia sido formulada nenhuma teoria explicativa sobre coligações, sendo as análises anteriores de cunho ensaístico, que, com frequência, viam as alianças como indicador da falência dos partidos, da ausência de ideologia partidária, e ainda como atestado da irracionalidade do sistema político (Soares, 1973a). Nesse sentido a pesquisa citada visava preencher esta lacuna, apresentando as coligações como um fenômeno racional, previsível e explicável, dentro do contexto da problemática de classes.

Para isso, o autor analisou os dados sobre a Câmara Federal e Assembleias Estaduais, com ênfase nos maiores partidos, formulando o que chamou de teoria da resistência ideológica e do esforço mínimo. De acordo com a primeira, cada partido possui raízes sociais e plataforma ideológica suficientemente claras, que o diferencia dos demais, e influenciam nas decisões de participação ou não de coligações, e de quais parceiros escolher. Já conforme a segunda perspectiva, os partidos buscam maximizar o seu desempenho eleitoral através das alianças partidárias, otimizando seus ganhos com o menor esforço possível. A forma pela qual Soares (2001) compreende a interação entre essas duas teorias é exemplificada na afirmação abaixo:

A aplicação da teoria dos jogos ao processo eleitoral, divorciada do conteúdo ideológico dos partidos e da estrutura dos interesses, pode levar a paradoxos. Podemos imaginar um partido trabalhista que, para vencer as eleições, se alia a um grupo conservador que é majoritário na coligação, comprometendo-se assim a abandonar a defesa dos interesses da classe trabalhadora. O eleitoralismo puro e simples seria exatamente isto. Mas o processo político não se reduz ao processo eleitoral: não começa nele e não termina com as eleições. A ideologia introduz na racionalidade política uma perspectiva temporal que inclui a própria racionalidade eleitoral. É uma racionalidade de meios a partir de fins. Os fins são ideologicamente definidos (idem, p. 169).

\footnotetext{
de 1945-1947 já imprimiam a nova configuração eleitoral do país (Lima Júnior, 1983, p.63). No entanto, foram permitidas pela primeira vez em nível nacional apenas nas eleições de 1950, vigorando até 1962. Em 1971, a Lei Orgânica dos Partidos Políticos as proibiu, sendo liberadas em 1986. Até 1998, as alianças para a Câmara dos Deputados teriam de ser congruentes com as formadas nas eleições para os Governos dos Estados. De 2002 a 2006, vigorou a chamada Lei da Verticalização, instituída pelo TSE. Com ela, os partidos que integrassem coligações presidenciais ficavam proibidos de se coligarem com partidos adversários nas disputas para os demais pleitos. Porém, o descontentamento com a Lei foi evidente e, ainda em 2006, os parlamentares aprovaram uma Emenda garantindo a liberdade na formação das alianças (Miranda, 2013, p.69).
} 
No entanto, embora a racionalidade eleitoral explique parcialmente a propensão de um partido coligar-se, segundo Soares (2001), não se deve concluir que diferentes eleições representam soluções exclusivamente conjunturais, que resolve problemas daquele partido, naquele lugar e naquela eleição. As coligações possuem certas estruturas que se repetem ao longo do tempo, tendo em vista que a) as opiniões políticas de um estado não são voláteis, havendo uma tendência a repetição das condições consideradas satisfatórias, b) há lealdades na política, o que facilita a reprodução das combinações anteriores, c) há uma base ideológica na política (Soares, 1973b, p.481-482; 2001, p.166). Desse modo, os partidos estruturados tendem a aliar-se com mais frequência nos estados onde se aliaram anteriormente ${ }^{7}$.

Resumindo, estes foram os achados de Soares, tendo como base o que ele chama de aplicação da teoria dos jogos ao estudo das alianças: os partidos pequenos se coligam mais que os grandes; em situação hegemônica, um partido não necessita aliar-se; as alianças são eleitoralmente mais significativas no nível federal do que estadual, e nas eleições majoritárias do que nas proporcionais. Já na perspectiva das ideologias, das bases sociais dos partidos, e dos condicionantes socioeconômicos, o autor destaca que: os partidos com bases amplas sofrem menos entraves para aliar-se; os partidos em regiões mais desenvolvidas tendem a coligar-se menos do que os das áreas menos desenvolvidas, sendo mais fiéis à composição de classe do eleitorado e mais preocupados com uma plataforma ideológica; o comportamento dos indivíduos é determinado pelo seu contexto social e econômico, ou seja, está sujeito à regularidades, do mesmo modo que as coligações eleitorais, que são produto de decisões humanas. (Soares, 1973a; 2001)

O argumento de Soares possibilitou um importante debate em torno do fenômeno coligacionista, com muito mais dissensos do que consensos. Isabel Oliveira (1973) refuta a proposição do autor, afirmando que o crescimento do número de coligações na Câmara Federal em 1950-1962 ocorreu efetivamente na região mais industrializada e urbanizada. Examina se existe ou não um padrão recorrente na formação das coligações e destaca:

(...) se fixarmos os anos e corrermos os dados em sentido vertical, veremos que raramente uma coligação envolvendo os partidos A e B se faz em mais

\footnotetext{
${ }^{7}$ Soares (1973, p.482-483), ao abordar as coligações como estruturas estáveis, utiliza o termo "estrutura nas coligações eleitorais" para se referir aos partidos que fizeram alianças em determinados estados em $\mathrm{t}$, e tornaram a fazê-las em $\mathrm{t}+1$, ao invés de concorrerem isoladamente. O autor trata de "casos inconsistentes", a situação oposta: partidos que formaram alianças em determinados estados em $t$, mas não o fizeram em $t+1$. Conforme pôde ser observado no rodapé 4 , a terminologia consistente e inconsistente dos estudos recentes sobre coligações possui outro significado, atrelado à ideologia partidária. Já, Soares utilizou o termo "coesão ideológica" (idem, p.474) para abordar os arranjos ideológicos das alianças. Para a discussão sobre os conceitos de consistência, coesão e coerência aplicado aos estudos coligacionais, ver Machado e Miguel (2008).
} 
de um Estado. Se fixarmos os Estados e corrermos os dados horizontalmente, veremos também que as coligações não se mantém no tempo, na sua grande maioria. Assim aparentemente, cada coligação seria específica a cada eleição e a cada Estado" (idem, p.174).

No entanto, a autora analisa apenas os três maiores partidos do período (PSD-centro, PTBliberal, e UDN-conservador), recorte que lhe rendeu críticas ${ }^{8}$.Salienta que é muito pequena a diferença entre as alianças ideológicas e não ideológicas, e aponta para tendência a formação de parcerias contendo um partido grande com um ou mais partidos pequenos. Conclui que as diferenças estruturais entre os estados não podem ser aceitas como fator explicativo da distribuição de alianças (Oliveira, 1973).

Em sintonia com o argumento acima, Lima Jr. (1983) centrou-se no debate das diferenciações que deveriam haver no cálculo coligacionista no que se refere ao nível eleitoral (estadual x federal) e ao tipo de eleição (majoritária x proporcional). Defende a ideia da existência de diferentes dinâmicas nos subsistemas partidários estaduais ${ }^{9}$ que influenciariam mais na decisão dos partidos de formar alianças do que a dinâmica partidária nacional, ou seja, tais decisões seriam orientadas por uma racionalidade contextual: as decisões de formar alianças foram racionais, em determinada conjuntura, porque tinham como principal objetivo maximizar o apoio eleitoral, e foram contextuais porque tomadas localmente à luz dos resultados da eleição previa, e não de acordo com uma estratégia partidária nacional. A força local relativa de um partido constitui-se no determinante principal de qualquer decisão sobre formação de alianças (idem, p.77).

Para ele, as teorias de Soares não seriam adequadas, pois assumira uma premissa de racionalidade política invariante, o que seria um equívoco já que o tamanho do partido não seria fixo no tempo, nem os níveis federal e estadual fariam parte do mesmo jogo (Lima Jr., 1983, p.45). O autor destaca que, quando Soares uniformizou os partidos em análise, não considerou o fato de que alguns destes sempre foram grandes, porém apenas no âmbito estadual. Como exemplos, cita o PR-mineiro, o PSP-paulista, e o PDC- São Paulo, Paraná e

\footnotetext{
${ }^{8}$ Entre estas destaca-se à apresentada por Santos (1987, p.112), ao ressaltar que apesar da força eleitoral desses três partidos, as coligações permitiram que partidos inexpressivos eleitoralmente tivessem representação, de modo que essa "licença democrática" foi significativa para a sobrevivência de pequenos partidos.

${ }^{9}$ Lima Júnior (1983) discute os diversos sistemas partidários a nível nacional e estadual. Defende o argumento de que o sistema multipartidário excessivamente fragmentado, uma das variáveis explicativas mais importantes para a quebra do regime democrático, não se sustentava, tendo em vista o número de partidos efetivamente existentes, medidos pelo seu grau de competitividade. As alianças eleitorais são utilizadas pelo autor afim de comprovar sua tese. Observa a prevalência de três subsistemas partidários: bipartidário, multipartidário moderadamente fragmentado e multipartidário altamente fragmentado.
} 
Rio Grande do Sul. Por isso, uma análise adequada exigiria a incorporação destes elementos, ou seja, deveria ser contextualizada. Somam-se às críticas, o fato de que Soares também deixou de lado em suas análises os pequenos partidos.

A força relativa dos partidos constitui-se em um conceito central na argumentação de Lima Júnior. No entanto, a forma de operacionalização do conceito apresenta alguns problemas, que podem ter enviesado à análise. $\mathrm{O}$ autor ordena os partidos pelo número de votos recebidos, e os classifica em dois grandes grupos, de modo que os 5 primeiros partidos do ranking que receberam mais votos em $\mathrm{t}-1$ foram considerados "grandes", e o restante "pequenos" em t. Como resultado, foi constatado que quase 50\% das alianças ocorridas de 1950 a 1962 (48 do total de 91) se deram entre pelo menos um dos primeiros 5 partidos e um dos menores partidos; 18 parcerias foram entre o $1^{\underline{0}}$ e $2^{\underline{0}}$ maiores partidos, contradizendo sua previsão de que partidos formam alianças para derrotar o principal adversário; e apenas 6 alianças ocorreram entre pequenos partidos (Lima Jr., 1973, p.80). No entanto, não foi apresentado detalhadamente o universo empírico de sua pesquisa, de forma que não é possível identificar quantos e quais são os partidos menores. Como sinaliza Nicolau (2004), o número de partidos que disputaram as eleições de 1945 a 1962 foi 20, sendo que o total de partidos em cada eleição variou de 12 a 14. Assim, Lima Jr. estaria se referindo a algo em torno de 7 a 9 partidos pequenos em cada disputa. Cabe ainda salientar que as alianças realizadas entre o $5^{\circ}$ e o $6^{0}$ colocados seriam classificadas como uma união de um grande partido com pequeno, independentemente do tamanho da diferença dos votos recebidos por estes.

Lima Jr. criticou Soares quanto à racionalidade política invariante, apresentando a racionalidade contextual como uma proposta alternativa. Porém, a força do argumento do tamanho relativo dos partidos, parece ser reduzida quando observado às suas escolhas metodológicas: os partidos podem ter tamanhos distintos de acordo com os diferentes níveis de competição, os Estados, e ao longo do tempo, mas a mensuração dessas diferenças via ranking ( $1^{\circ}$ a $5^{\underline{0}}$ maiores partidos e os pequenos), e análises de interação a partir deste critério, não vão ao encontro do poder heurístico de seu conceito. Soma-se a isso o fato da agregação das eleições, já que o autor se concentra no número total de alianças do período estudado, em uma análise que pretende destacar as racionalidades contextuais.

Por fim, cabe mencionar que Soares e Lima Jr. destacam o fato de que, na formação de coligações, as informações são incompletas ${ }^{10}$, o que poderia influenciar negativamente na tomada de decisão da cúpula partidária, e o mesmo não ocorreria nas análises das

\footnotetext{
${ }^{10}$ Esta questão possui uma vasta discussão no âmbito da teoria da escolha racional e teoria dos jogos, principalmente entre os economistas, que não faz parte do escopo deste trabalho. Para este debate, ver Downs (1957, p.163) e Neumann e Morgenstern (1944).
} 
coalizões. Talvez, a título meramente reflexivo, a racionalidade contextual de Lima Jr. seja um subproduto da informação, no contexto da teoria da escolha racional.

À luz da teoria de Soares sobre as coligações pragmáticas e ideológicas, e da ideia de racionalidade contextual de Lima Jr., o próximo tópico é dedicado ao estudo das alianças realizadas pelo PSB nas eleições majoritárias estaduais, de 1990 a 2014.

\section{O PSB e suas alianças eleitorais}

O universo empírico desta pesquisa compreende 189 coligações $^{11}$, no entanto, o partido deixou de se apresentar em 17 ocasiões, e em outras 10 concorreu sozinho, reduzindo este universo para 162 coligações. O PSB se coligou a 43 legendas durante o período estudado, as quais são apresentadas no quadro 1 .

Em função do grande número de siglas, fusões, cisões e modificações de nomenclatura, principalmente entre os partidos de direita, muitos entraves são evidenciados ao pesquisador, especialmente quando se pretende realizar uma análise longitudinal, e algumas escolhas metodológicas fizeram-se necessárias. Primeiramente, optou-se por unificar somente as legendas que sofreram alterações de nomenclatura, mas que se mantiveram no mesmo espectro ideológico (caso do PFL/DEM, sendo os dados unificados; porém, o PSN, direita, passou a ser PHS, esquerda, em 1997, contudo, os dois partidos não foram agrupados), e as fusões que não se sobrepuseram ao longo do tempo (por exemplo, o PP e o PPB foram agrupados porque não tiveram dados eleitorais/coligacionais coincidentes em nenhuma eleição quando eram duas legendas independentes, ou seja, não competiram entre si nas eleições para Governador no período analisado; isto não ocorreu quando observada a relação do PP com o PST, motivo pelo qual este último fora analisado separadamente).Em segundo lugar, os partidos que se aliaram ao PSB somente em uma eleição não serão analisados ${ }^{12}$, já que não fornece instrumentos para a análise proposta - fidelidade aliancista. Por fim, como já fora enfatizado, optou-se por analisar as alianças de forma desagregada ${ }^{13}$.

\footnotetext{
${ }^{11}$ As coligações feitas pelo PSB para o Executivo Federal (1990-2014), bem como àquelas que tiveram sucesso eleitoral, podem ser observadas no Anexo 1. No entanto, não faz parte do escopo deste trabalho avaliar o êxito ou não da prática de fidelidade aliancista.

${ }^{12}$ Estes partidos são: a) PEB - formou apenas uma aliança com o PSB, em 1990, no Distrito Federal; b) PDC - realizou
uma única parceria, em 1990, em Rondônia; c) PPR - foram duas parcerias em 1994, no Maranhão e Paraná; d) PSN -
formou seis alianças em 1998; e) PROS - foram sete alianças em 2014; f) SD - realizou onze parcerias em 2014; g) PEN
- dez alianças em 2014; h) PPL - sete alianças em 2014; i) PSOL - uma única parceria, em 2014; j) PSTU - cinco alianças
em 1994; k) PS - apenas uma em 1990 .
${ }^{13}$ Uma opção para apresentar as alianças eleitorais de modo desagregado seria em formato de matriz (partido x partido),
conforme foi utilizado por Dantas (2007), em que os estados onde ocorreu a combinação partidária são destacados. Esta
} 
Quadro 1 - Espectro ideológico ${ }^{14}$ dos partidos políticos que se coligaram ao PSB

\begin{tabular}{llllllllll}
\hline & PL & PPR & PEB & PTB & PST & PDC & PRONA & PTC/PRN & PGT \\
Direita & PSL & PTN & PSN & PRP & PTdoB & PAN & PSC & PP/PPB & PSDC \\
& PSD15 & PR & PRTB & SD & PROS & PEN & PRB & PFL/DEM & \\
\hline Centro & PMDB & PSDB & & & & & & & \\
\hline \multirow{2}{*}{ Esquerda } & PT & PCB & PCdoB & PV & PDT & PS & PMN & PSTU & PPS \\
& PPL & PSOL & PHS & & & & & & \\
\hline
\end{tabular}

Fonte: Elaboração própria

As figuras 1, 2 e 3, servirão para o conjunto desta análise. No entanto, cabe antes enfatizar que as eleições de 2002 e 2006 ocorreram sob a regulação da verticalização, modificando bastante a configuração das coligações no país ${ }^{16}$. No caso específico do PSB, em 2002, como lançou candidato próprio à Presidência da República, fora impedido de se aliar a seus concorrentes nos demais pleitos, de forma que seus parceiros para as eleições executivas estaduais foram predominantemente o PGT e o PTC (membros da coligação presidencial), além de outros pequenos partidos. Contudo, tal estratégia foi modificada para as eleições de 2006, em que apoiou apenas informalmente a candidatura de Lula pelo PT, ficando livre para escolher seus parceiros em outros pleitos. Em uma análise preliminar, à margem da perspectiva coligacional, o PSB foi mais bem-sucedido em 2002 (elegeu 4 governadores) do que em 2006 (elegeu 3 governadores), porém, no primeiro caso não participou de nenhuma outra coligação vitoriosa (pertencente à chapa do executivo estadual eleito), enquanto que no segundo caso foram 7 outras coligações vitoriosas, com prováveis benefícios via cargos ou apoio eleitoral em outras disputas.

seria uma opção interessante para visualização das alianças, mas demandaria a confecção de uma matriz para cada eleição, e não contemplaria a perspectiva longitudinal, central para esta análise. Por isso, optou-se por apresentar os dados em fluxogramas rotulados.

\footnotetext{
${ }^{14}$ Há uma vasta discussão sobre classificação ideológica dos partidos políticos brasileiros. No entanto, para este trabalho, será utilizada a classificação elaborada por Krause, Dantas e Miguel (2010).

${ }^{15}$ Partido criado em 1987, utilizou a mesma sigla do velho PSD (Arena), e em 2002 disputou sua última eleição, já que foi incorporado ao PTB em 2003. No entanto, a sigla retorna nas eleições de 2014, porém, trata-se de um novo partido, que não será aqui analisado, embora seja possível observar suas coligações com o PSB no anexo 1.
}

${ }^{16}$ Sobre os efeitos da lei da verticalização nas coligações nas eleições proporcionais, ver Fleisher (2010). 
Figura 1 - Partidos de direita que se aliaram ao PSB nas eleições majoritárias estaduais*

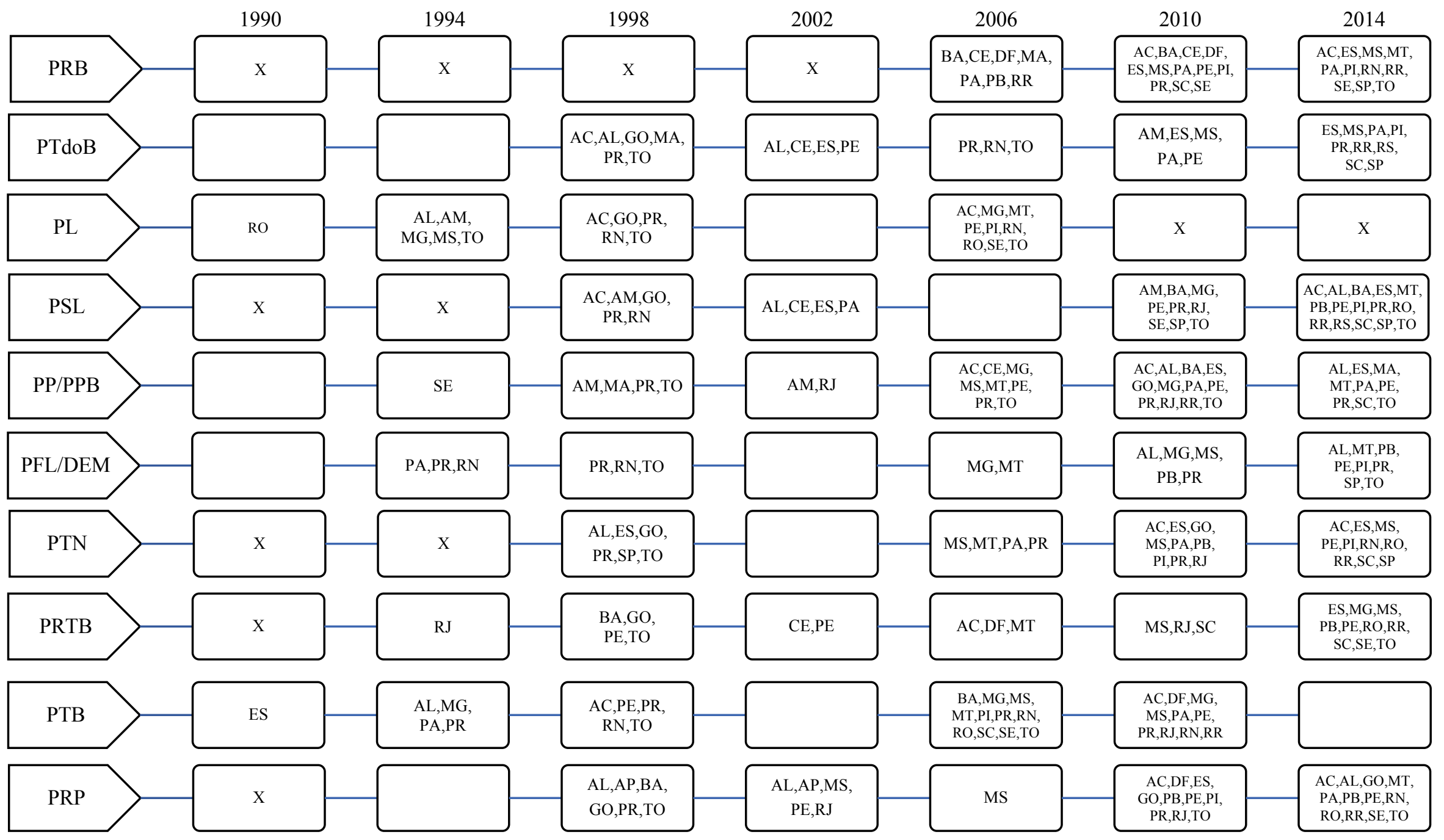




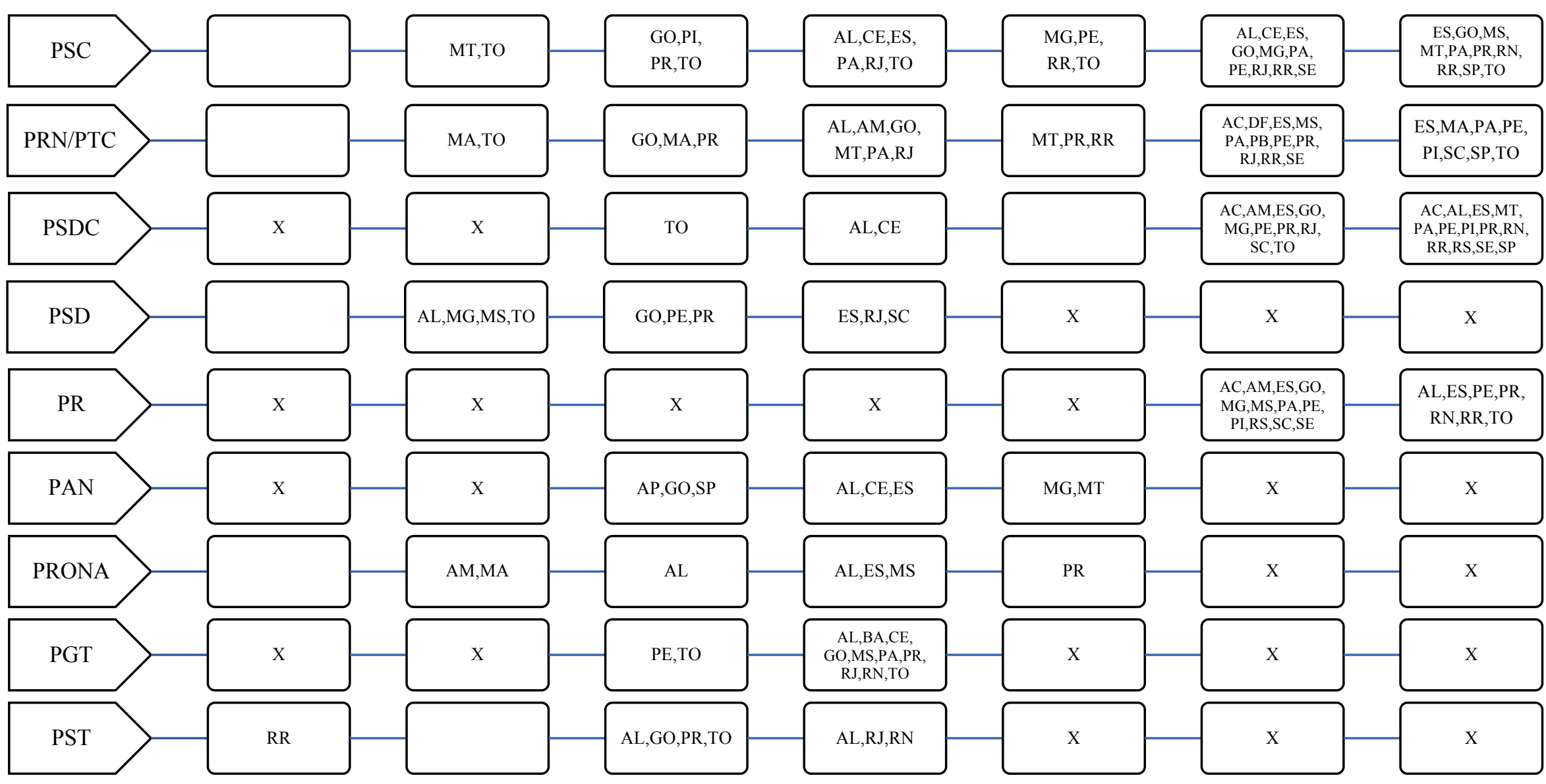

Fonte: Elaboração própria (TSE)

${ }^{*} \mathrm{X}=$ inexistência da legenda; Célula vazia=ausência de coligação

Figura 2- Partidos de centro que se aliaram ao PSB nas eleições majoritárias estaduais* 


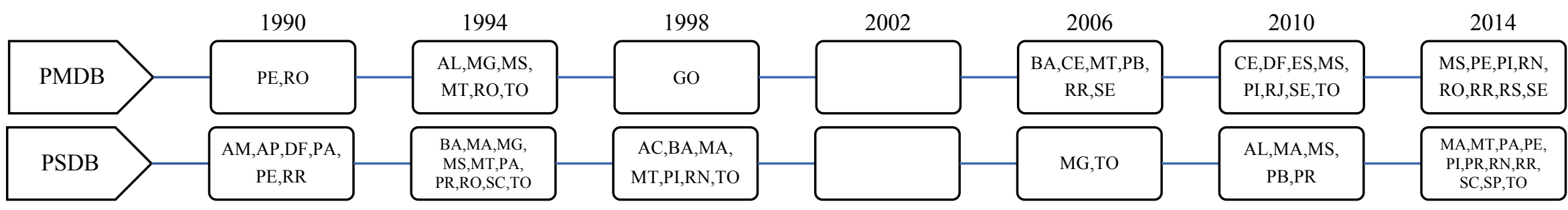

Fonte: Elaboração própria (TSE)

${ }^{*} X=$ inexistência da legenda; Célula vazia=ausência de coligação

Figura 3- Partidos de esquerda que se aliaram ao PSB nas eleições majoritárias estaduais*

\begin{tabular}{|c|c|c|c|c|c|c|c|}
\hline & 1990 & 1994 & 1998 & 2002 & 2006 & 2010 & 2014 \\
\hline PCB & $\begin{array}{c}\text { AL,AM,AP,BA,CE, } \\
\text { DF,MG,MS,MT,PA, } \\
\text { PB,PE, SP }\end{array}$ & PA,SP & $\begin{array}{l}\text { CE,DF,MG, } \\
\text { PA,PE,RJ, } \\
\text { RS,SC,SE }\end{array}$ & & & & \\
\hline PDT & $\begin{array}{l}\text { AM,DF,ES,MA, } \\
\text { MT,PA,PE, PI,RR }\end{array}$ & $\begin{array}{l}\text { AP,MG,MT,PA, } \\
\text { PE,PR,SC,SE,TO }\end{array}$ & $\begin{array}{c}\text { AC,AL,AM,BA,CE, } \\
\text { DF,MA,MG,PE,RJ, } \\
\text { SC,SE,SP,TO }\end{array}$ & & PE,PR,RO & $\begin{array}{l}\text { AC,AM,BA,CE,DF, } \\
\text { ES,GO,MG,MT,PA, } \\
\text { PB,PE,RJ,SE,TO }\end{array}$ & $\begin{array}{c}\text { AC,DF,MA, } \\
\text { MT,PB,PI,RN, } \\
\text { RO,SE,TO } \\
\end{array}$ \\
\hline PCdoB & $\begin{array}{c}\text { AL,AM,AP,BA,CE, } \\
\text { DF,ES,MA,MG,MS, } \\
\text { MT,PA,PB,PE,PI, } \\
\text { RN,RR,SE,SP }\end{array}$ & $\begin{array}{c}\text { AC,AL,AM,AP,BA, } \\
\text { CE,DF,ES,MG, } \\
\text { MS,MT,PB,PE,RJ,R } \\
\text { S,SC,SE,SP,TO } \\
\end{array}$ & $\begin{array}{l}\text { AC,AL,AM,AP,CE, } \\
\text { DF,ES,MG,PA,PB, } \\
\text { PE,RJ, RS,SC,SE }\end{array}$ & & $\begin{array}{l}\text { AC,BA,CE,DF,GO, } \\
\text { MA,MS,PA,PB,PI, } \\
\text { RJ, RN,RR,SE }\end{array}$ & $\begin{array}{c}\text { AC,BA,CE,DF,ES, } \\
\text { MA,PA,PE,PI,RJ, } \\
\text { RS,SC,SE,TO }\end{array}$ & $\begin{array}{l}\text { AC,AP,ES, } \\
\text { MA,PB,PE, } \\
\text { PI,RJ,RO,SE } \\
\end{array}$ \\
\hline PT & $\begin{array}{c}\text { AL,AM,AP,CE,GO, } \\
\text { MA,MG,MS,MT, } \\
\text { PA,PB,PI,PR,RJ, } \\
\text { RN,SE,SP } \\
\end{array}$ & $\begin{array}{l}\text { AC,AP,BA,CE,DF,E } \\
\text { S,MG,MT,PB,PE,PI, } \\
\text { RJ,RS,SC,SE,SP }\end{array}$ & $\begin{array}{l}\text { AC,AL,AM,AP,CE, } \\
\text { DF,ES,MG,PA,PB, } \\
\text { PE,PI,RJ,RS,SC,SE }\end{array}$ & & $\begin{array}{c}\text { AC,BA,CE,DF,GO, } \\
\text { MA,MS,PA,PB,PI, } \\
\text { RJ,RN,RR,SE }\end{array}$ & $\begin{array}{c}\text { AC,AM,AP,BA,CE, } \\
\text { DF,ES,PA,PE,PI, } \\
\text { RJ,RN,RO,RR,RS, } \\
\text { SC.SE,TO } \\
\end{array}$ & $\begin{array}{l}\text { AC,AP,PB, } \\
\text { RJ,SE }\end{array}$ \\
\hline PV & & $\begin{array}{c}\text { AC,AP,BA,MS,MT, } \\
\text { PB,PE,PR, } \\
\text { RJ,RS }\end{array}$ & $\begin{array}{c}\text { AC,AL,AP,BA, } \\
\text { CE,DF,MG,MT, } \\
\text { PB,RN,TO } \\
\end{array}$ & $\begin{array}{c}\text { AL,AM, } \\
\text { DF,ES }\end{array}$ & $\begin{array}{c}\text { BA,CE,DF,MT, } \\
\text { RR,TO }\end{array}$ & $\begin{array}{c}\text { AC,ES,MT, } \\
\text { PA,PB }\end{array}$ & $\begin{array}{l}\text { ES,MT,PB, } \\
\text { PE,PI,RJ,RN }\end{array}$ \\
\hline PMN & $\mathrm{PE}, \mathrm{RO}$ & $\begin{array}{c}\text { AM,MG,MT, } \\
\text { PE,SE,SP }\end{array}$ & $\begin{array}{c}\text { AC,AL,AM, } \\
\text { BA,DF,ES,MA, } \\
\text { MT,PE,SC } \\
\end{array}$ & & $\begin{array}{c}\text { AC,BA,CE, } \\
\text { MA,MT,PR, } \\
\text { RN,RR } \\
\end{array}$ & MG,MS,PR,RJ & $\begin{array}{l}\text { ES,PA,PI,PR,RN, } \\
\text { RR,SP }\end{array}$ \\
\hline
\end{tabular}




\begin{tabular}{|c|c|c|c|c|c|c|c|}
\hline PHS & $X$ & X & & $\begin{array}{c}\text { AL,CE,DF,ES, } \\
\text { MT,PA,TO }\end{array}$ & $\begin{array}{l}\text { CE,MG, } \\
\text { MS,RN }\end{array}$ & $\begin{array}{c}\text { AC,BA,DF,ES,MS, } \\
\text { PA,PE,PR, } \\
\text { RJ,RR,SC,TO }\end{array}$ & $\begin{array}{c}\text { AC,ES,MS, } \\
\text { PB,PE,PR,RN, } \\
\text { RR,RS,SC,TO }\end{array}$ \\
\hline PPS & $X$ & $\begin{array}{c}\text { AM,BA,CE,DF, } \\
\text { MG,MT,PA,PE,PR, } \\
\text { RS,SC,SP }\end{array}$ & $\begin{array}{c}\text { AC,AL,AM, } \\
\text { AP,BA,GO, } \\
\text { PR,SC }\end{array}$ & & $\begin{array}{c}\text { BA,MG,MT, } \\
\text { RN,RR }\end{array}$ & $\begin{array}{l}\text { AL,DF,MA, } \\
\text { MG,MS,MT, } \\
\text { PB,PR,RN,TO }\end{array}$ & $\begin{array}{l}\text { AL,ES,MA,MT,PA, } \\
\text { PE,PI,PR,RN,RR, } \\
\text { RS,SC,SP,TO }\end{array}$ \\
\hline
\end{tabular}

Fonte: Elaboração própria (TSE)

${ }^{*} X=$ inexistência da legenda; Célula vazia=ausência de coligação 


\section{A)Perfil geral das alianças}

Com base na observação das figuras é possível perceber dois perfis distintos de alianças eleitorais do partido socialista: a) nas três primeiras eleições, o PSB se aliou predominantemente com partidos localizados no mesmo espectro ideológico, com destaque às parcerias com o PT e o PCdoB; b) a partir de 2006, as alianças com partidos de direita foram intensificadas, superando às realizadas com partidos de esquerda, e perpassando a maioria das legendas de maneira relativamente equânime. Contudo, cabe destacar que as alianças do PSB com partidos do polo oposto, no primeiro perfil, foram bem reduzidas quando comparadas às alianças deste partido com a esquerda, no segundo perfil. Ou seja, a partir das eleições de 2006, o partido optou por mesclar mais suas parcerias. Em relação às alianças com partidos de centro, estas não sofreram grandes alterações ao longo do período analisado, embora, nas eleições de 2014, seja possível observar um importante crescimento.

Estes dois perfis vão ao encontro dos verificados por Krause e Godoi (2010, p.68), que, através de análise das coligações de modo agregado, salientaram a preferência do PSB por partidos de esquerda em 1990 e 1994 (consistentes ideologicamente), e por coligações inconsistentes de 1998 a 2006. No entanto, os dados aqui apresentados demonstram maior intensidade de alianças com partidos de esquerda também em 1998, embora haja um crescimento considerável de parceiros de direita já nestas eleições.

Por fim, para uma compreensão complementar do que estes perfis podem indicar, o modelo analítico sobre o desenvolvimento das organizações partidárias elaborado por Panebianco (2005) pode ser uma importante ferramenta. Segundo o autor, tal desenvolvimento se daria em três etapas. A primeira corresponde ao momento de gênese (fundação) em que o aspecto ideológico é utilizado como incentivo coletivo. A segunda constitui o processo de institucionalização, compreendido como a consolidação da organização, ou ainda "a passagem de uma fase de fluidez estrutural inicial, quando a recém-nascida organização ainda se encontra em construção, a uma fase em que a organização se estabiliza, desenvolve interesses estáveis para a sobrevivência e lealdades organizativas estáveis" (idem, 1990, p.36). A última fase de desenvolvimento é a maturidade, fase em que o partido substitui a ideologia manifesta presente em sua gênese por uma ideologia latente, que só será explicitada para a aquisição de fins específicos. Contudo, não se pretende adentrar na perspectiva organizacional do PSB, nem tampouco na discussão sobre institucionalização partidária. Cabe aqui apenas destacar que a preponderância de alianças com partidos de esquerda nos anos iniciais da vida do PSB, conforme fora observado, e as mudanças posteriores em suas parcerias podem indicar uma transformação maior nesta organização partidária. 


\section{B) As alianças nos Estados e no Distrito Federal}

A tabela 1 apresenta o total de alianças do PSB com cada um dos partidos nas Unidades Federativas (UF's). As lacunas visualizadas onde estão alocados os partidos de direita sinalizam para menor incidência deste perfil de aliança (PSB com polo oposto), e que o oposto ocorre quando observada as parcerias entre PSB e partidos de esquerda. Olhando para a presença de uma mesma aliança nas UF's, é notória a "capilaridade aliancista" deste último grupo, sendo a parceria PSB+PT um caso emblemático, já que se fez presente, e de maneira intensa, em todos os Estados e no Distrito Federal.

Tabela 1 - Número total de alianças do PSB nas eleições para Governador (1990-2014)

\begin{tabular}{|c|c|c|c|c|c|c|c|c|c|c|c|c|c|c|c|c|c|c|c|c|c|c|c|c|c|c|c|c|c|}
\hline \multirow{2}{*}{\multicolumn{2}{|c|}{ Partidos/UF }} & \multicolumn{3}{|c|}{ Sul } & \multicolumn{4}{|c|}{ Sudeste } & \multicolumn{4}{|c|}{ Centro-Oeste } & \multicolumn{7}{|c|}{ Norte } & \multicolumn{9}{|c|}{ Nordeste } & \multirow{2}{*}{ TOTAL } \\
\hline & & $\mathrm{RS}$ & $\mathrm{SC}$ & PR & SP & RJ & $\overline{M G}$ & ES & MS & MT & $\overline{\mathrm{GO}}$ & $\overline{\mathrm{DF}}$ & $\mathrm{RO}$ & $\overline{\mathrm{AC}}$ & $\overline{\mathrm{AM}}$ & $\overline{R R}$ & $\mathrm{PA}$ & $\overline{\mathrm{AP}}$ & $\mathrm{TO}$ & MA & PI & CE & RN & PB & $\mathrm{PE}$ & $\mathrm{AL}$ & SE & $\mathrm{BA}$ & \\
\hline \multirow{20}{*}{ 苟 } & PRB & & 1 & 1 & 1 & & & 2 & 2 & 1 & & 2 & & 2 & & 2 & 3 & & 1 & 1 & 2 & 2 & 1 & 1 & 1 & & 2 & 2 & 30 \\
\hline & PTdoB & 1 & 1 & 3 & 1 & & & 3 & 2 & & 1 & & & 1 & 1 & 1 & 2 & & 2 & 1 & 1 & 1 & 1 & & 2 & 2 & & & 27 \\
\hline & PL & & & 1 & & & 2 & & 1 & 1 & 1 & & 2 & 2 & 1 & & & & 3 & & 1 & & 2 & & 1 & 1 & 1 & & 20 \\
\hline & PSL & 1 & 1 & 3 & 2 & 1 & 1 & 2 & & 1 & 1 & & 1 & 2 & 2 & 1 & 1 & & 2 & & 1 & 1 & 1 & 1 & 2 & 2 & 1 & 2 & 33 \\
\hline & PP/PPB & & 1 & 4 & & 2 & 2 & 2 & 1 & 2 & 1 & & & 2 & 2 & 1 & 2 & & 4 & 2 & & 1 & & & 3 & 2 & 1 & 1 & 36 \\
\hline & PFL/DEM & & & 4 & 1 & & 2 & & 1 & 2 & & & & & & & 1 & & 2 & & 1 & & 2 & 2 & 1 & 2 & & & 21 \\
\hline & PTN & & 1 & 3 & 2 & 1 & & 3 & 3 & 1 & 2 & & 1 & 2 & & 1 & 2 & & 1 & & 2 & & 1 & 1 & 1 & 1 & & & 29 \\
\hline & PRTB & & 2 & & & 2 & 1 & 1 & 2 & 1 & 1 & 1 & 1 & 1 & & 1 & & & 2 & & & 1 & & 1 & 3 & & 1 & 1 & 23 \\
\hline & РTB & & 1 & 4 & & 1 & 3 & 1 & 2 & 1 & & 1 & 1 & 2 & & 1 & 2 & & 2 & & 1 & & 3 & & 2 & 1 & 1 & 1 & 31 \\
\hline & PRP & & & 2 & & 2 & & 1 & 2 & 1 & 3 & 1 & 1 & 2 & & 1 & 1 & 2 & 3 & & 1 & & 1 & 2 & 3 & 3 & 1 & 1 & 34 \\
\hline & PSC & & & 2 & 1 & 2 & 2 & 3 & 1 & 2 & 3 & & & & & 3 & 3 & & 5 & & 1 & 2 & 1 & & 2 & 2 & 1 & & 36 \\
\hline & PRN/PTC & & 1 & 3 & 1 & 2 & & 2 & 1 & 2 & 2 & 1 & & 1 & 1 & 2 & 3 & & 2 & 3 & 1 & & & 1 & 2 & 1 & 1 & & 33 \\
\hline & PSDC & 1 & 1 & 2 & 1 & 1 & 1 & 2 & & 1 & 1 & & & 2 & 1 & 1 & 1 & & 2 & & 1 & 1 & 1 & 2 & 1 & 2 & 1 & & 27 \\
\hline & PSD & & 1 & 1 & & 1 & 1 & 1 & 1 & & 1 & & & & & & & & 1 & & & & & & 1 & 1 & & & \\
\hline & PR & 1 & 1 & 1 & & & 1 & 2 & 1 & & 1 & & & 1 & 1 & 1 & 1 & & 1 & & 1 & & 1 & & 2 & 1 & 1 & & 19 \\
\hline & PAN & & & & 1 & & 1 & 1 & & 1 & 1 & & & & & & & 1 & & & & 1 & & & & 1 & & & 8 \\
\hline & PRONA & & & 1 & & & & 1 & 1 & & & & & & 1 & & & & & 1 & & & & & & 2 & & & 7 \\
\hline & PGT & & & 1 & & 1 & & & 1 & & 1 & & & & & & 1 & & 2 & & & 1 & 1 & & 1 & 1 & & 1 & 12 \\
\hline & PST & & & 1 & & 1 & & & & & 1 & & & & & 1 & & & 1 & & & & 1 & & & 2 & & & 8 \\
\hline & TOTAL & 4 & 12 & 37 & 11 & 17 & 17 & 27 & 22 & 17 & 21 & 6 & 7 & 20 & 10 & 17 & 23 & 3 & 36 & 8 & 14 & 11 & 17 & 11 & 28 & 27 & 12 & 9 & 444 \\
\hline \multirow{3}{*}{ 竘 } & PMDB & 1 & & & & 1 & 1 & 1 & 3 & 2 & 1 & 1 & 3 & & & 2 & & & 2 & & 2 & 2 & 1 & 1 & 2 & 1 & 3 & 1 & 31 \\
\hline & PSDB & & 2 & 3 & 1 & & 2 & & 2 & 3 & & 1 & 1 & 1 & 1 & 2 & 3 & 1 & 4 & 4 & 2 & & 2 & 1 & 2 & 1 & & 2 & 41 \\
\hline & TOTAL & 1 & 2 & 3 & 1 & 1 & 3 & 1 & 5 & 5 & 1 & 2 & 4 & 1 & 1 & 4 & 3 & 1 & 6 & 4 & 4 & 2 & 3 & 2 & 4 & 2 & 3 & 3 & 72 \\
\hline \multirow{9}{*}{ 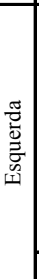 } & PCB & 1 & 1 & & 2 & 1 & 2 & & 1 & 1 & & 2 & & & 1 & & 3 & 1 & & & & 2 & & 1 & 2 & 1 & 1 & 1 & 24 \\
\hline & PDT & & 2 & 2 & 1 & 2 & 3 & 2 & & 4 & 1 & 4 & 2 & 3 & 3 & 1 & 3 & 1 & 4 & 3 & 2 & 2 & 1 & 2 & 5 & 1 & 4 & 2 & 60 \\
\hline & PCdoB & 3 & 3 & & 2 & 5 & 3 & 5 & 3 & 2 & 1 & 5 & 1 & 5 & 3 & 2 & 4 & 4 & 2 & 4 & 4 & 5 & 2 & 5 & 5 & 3 & 6 & 4 & 91 \\
\hline & PT & 3 & 3 & 1 & 2 & 6 & 3 & 3 & 2 & 2 & 2 & 4 & 1 & 5 & 3 & 2 & 4 & 5 & 1 & 2 & 5 & 5 & 3 & 5 & 3 & 2 & 6 & 2 & 85 \\
\hline & PV & 1 & & 1 & & 2 & 1 & 3 & 1 & 5 & & 3 & & 3 & 1 & 1 & 1 & 2 & 2 & & 1 & 2 & 2 & 4 & 2 & 2 & & 3 & 43 \\
\hline & PMN & & 1 & 3 & 2 & 1 & 2 & 2 & 1 & 3 & & 1 & 1 & 2 & 2 & 2 & 1 & & & 2 & 1 & 1 & 2 & & 3 & 1 & 1 & 2 & 37 \\
\hline & PHS & 1 & 2 & 2 & & 1 & 1 & 3 & 3 & 1 & & 2 & & 2 & & 2 & 2 & & 3 & & & 2 & 2 & 1 & 2 & 1 & & 1 & 34 \\
\hline & PPS & 2 & 3 & 4 & 2 & & 3 & 1 & 1 & 4 & 1 & 2 & & 1 & 1 & 2 & 2 & 1 & 2 & 2 & 1 & 1 & 3 & 1 & 2 & 3 & & 2 & 47 \\
\hline & TOTAL & 11 & 15 & 13 & 11 & 18 & 18 & 19 & 12 & 22 & 5 & 23 & 5 & 21 & 14 & 12 & 20 & 14 & 14 & \begin{tabular}{|l|}
13 \\
\end{tabular} & 14 & 20 & 15 & 19 & 24 & 14 & 18 & 17 & 421 \\
\hline
\end{tabular}

Fonte: Elaboração própria (TSE)

Na perspectiva horizontal, constatou-se que: os partidos de direita que mais se aliaram ao PSB foram PP/PPB e PSC, com 36 alianças cada, seguido pelo PRP (34) e PSL (33); o PSDB fez mais parcerias com o partido socialista do que o PMDB (41 e 31, respectivamente); o PCdoB e o PT foram os parceiros mais frequentes do mesmo espectro ideológico (91 e85, respectivamente). Embora em números absolutos o PSB tenha realizado mais alianças com partidos de direita (444 a 421), o que se deve muito à maior oferta destes, a diferença entre 
as alianças com PCdoB e PT em relação às feitas com PP/PPB e PSC é bastante clara, mais que o dobro.

Passando à perspectiva vertical, os achados foram: as UF's que mais apresentaram alianças entre PSB e partidos de direita foram PR (38) e TO (36), e os menos foram AP (3), RS (5), DF e RO (7 em cada um); os Estados que mais apresentaram o arranjo PSB e partido de centro foram TO (6), MS e MT (5 cada); por fim, em relação às alianças com partidos de esquerda, no MT, DF, AC e PE foram mais de 20 em cada um, e apenas 5 em GO e RO. Tais dados sinalizam para semelhanças nos perfis aliancistas em algumas UF's: a) em um primeiro grupo de Estados (PR, TO, MS, GO, AL), as parcerias do PSB foram majoritariamente com partidos de direita, em detrimentos às alianças com a esquerda; $b$ ) em um segundo grupo (MT, DF, AC) foi possível identificar parcerias predominantemente entre o PSB e partidos do mesmo espectro ideológico, e poucas “inconsistentes"; c) por fim, no ES, PE e PA, houveram parcerias entre PSB e partidos de esquerda e direita em quantidades semelhantes.

De acordo com a tabela 1, foi na região Nordeste onde o PSB obteve as maiores quantidades de alianças com parceiros de mesmo espectro ideológico. É interessante pontuar que a relação deste partido com esta região do Brasil é um elemento central da sua história. O grupo dissidente advindo da UDN que fundou o PSB em 1947 era, em sua maioria, de origem nordestina (João Mangabeira, Hermes Lima, Osório Borba), assim como suas primeiras lideranças (Francisco Julião, Barbosa Lima Sobrinho), conforme salienta Gustin e Vieira (1995). Com o regresso das instituições democráticas, o PSB foi refundado no ano de 1985. A recomposição do partido foi liderada por Roberto Amaral, político cearense experiente que havia construído carreira no PCB e no PCBR (Partido Comunista Brasileiro Revolucionário). A convite de Amaral, o cearense Miguel Arraes migra do PMDB para o PSB em 1990. Político experiente com capital político consolidado no estado de Pernambuco, foi eleito deputado federal, em 1990, com a maior votação no Brasil, conseguindo eleger outros quatro deputados com a votação obtida. Em termos ideológicos, sua trajetória foi marcada por proximidades com o PCB e envolvimento com as Ligas Camponesas. A migração de Arraes representou um ponto de inflexão no processo de consolidação do PSB, pois ao longo dos anos de 1990, e boa parte dos anos 2000, foi no estado de Pernambuco, que o partido apresentou os melhores resultados eleitorais na Câmara dos Deputados, na assembleia estadual, e também no executivo estadual. Em outros estados nordestinos como o Ceará e o Rio Grande do Norte, o partido apresentou um processo de crescimento semelhante. A notoriedade que o PSB adquiriu na região Nordeste nos últimos 
anos o coloca como uma espécie de "novo PFL" devido a sua forte característica regionalista ${ }^{17}$.

\section{c) Fidelidade Aliancista e o caso do PSB}

Até aqui foram apresentadas sinalizações de que, ao menos para o caso do PSB, as alianças eleitorais possuem vínculos de fidelidade nos estados. Para mensurar a intensidade destes vínculos, utiliza-se o seguinte cálculo:

$$
F A_{P 1, P 2}=\frac{x}{n(t)} \text {, sendo } x=A \cap B
$$

\section{Onde:}

$F A=$ fidelidade aliancista

$P 1=$ partido 1

P2 = partido 2

$A=U F^{\prime}$ s em que a aliança $P 1+P 2$ ocorreu na eleição em análise $(t)$

$B=U F^{\prime}$ s em que a aliança $P 1+P 2$ ocorreu na eleição anterior $(t-1)$

$n(t)=$ número total de alianças de $P 1+P 2$ na eleição em análise $(t)$

Nesta perspectiva, admite-se que as informações dos partidos na decisão de se coligar são também retroativas e cumulativas. A fidelidade aliancista varia de 0 a 1 , sendo que na situação hipotética de $F A=1$, indicaria que a aliança entre $P 1$ e $P 2$ em $t$ - 1 se repetiu em todas as UF's em $t$. Lembrando que o resultado apresentado está ponderado, de forma que ter $100 \%$ de fidelidade entre $P 1$ e $P 2$ pode significar que houve apenas 1 aliança em $t$, mas que fora repetida em $t$-1 (caso do PSB+PRP em 2006). Para uma melhor compreensão da tabela,

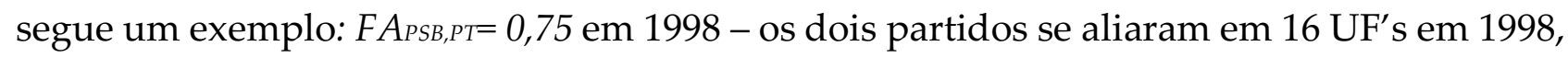
sendo que em 12 destas UF's já haviam se aliado em 1994 (12/16=0,75), indicando que 75\% das alianças entre estes dois partidos em 1998 já se faziam presentes em 1994, ou seja, se referem às alianças replicadas nas UF's. É importante enfatizar que, o denominador da equação da fidelidade aliancista é o número de alianças entre os dois partidos na eleição em análise (quantidade de UF's em que os dois partidos se aliaram), e não o número total de alianças possíveis (o total de UF's do Brasil). Esta confusão poderia levar a uma avaliação

\footnotetext{
${ }^{17} \mathrm{O}$ PFL foi definido como o partido dos grotões do Brasil, devido ao seu desenvolvimento fortemente atrelado à região (Lamounier e Meneguello, 1986).
} 
equivocada de que, ainda segundo o exemplo acima, PSB e PT se aliaram em 75\% das UF's do país em 1998, ou seja, em 20,25 dos 27 estados.

Dito isto, a tabela 2 apresenta os resultados da fidelidade aliancista entre o PSB e todos os seus parceiros nas eleições para o executivo estadual. Em virtude das lacunas no banco de dados (seja pela ausência de coligações em determinadas eleições, pela escolha metodológica quanto ao manuseamento das fusões e cisões, ou ainda em razão dos efeitos da verticalização), optou-se por abrir a seguinte exceção: conforme enfatizado anteriormente, em 2002 vigorou a lei da verticalização, e o PSB apresentou candidato próprio à Presidência, contando com o apoio de partidos pequenos (PTC e PGT), os quais foram seus principais aliados nas eleições para Governador daquele ano. Como o cálculo da fidelidade aliancista depende de um referencial em $t-1$, o que não haveria para a maioria dos partidos em 2002, optou-se por utilizar $t-2$ somente nesta situação. Isto parece razoável quando se pretende verificar laços de fidelidade entre os partidos no interior dos estados, de forma que, por mais que tenha havido mudança nas regras em 2002, e que neste contexto a decisão sobre coligações tenha sido tomada pela cúpula nacional dos partidos, estes laços puderam ser retomados nas eleições seguintes com a mudança no cenário.

Tabela 2 - Fidelidade coligacional entre o PSB e demais partidos*

\begin{tabular}{lccccccc}
\hline ALIANÇA & $\mathbf{1 9 9 4}$ & $\mathbf{1 9 9 8}$ & $\mathbf{2 0 0 2}$ & $\mathbf{2 0 0 6}$ & $\mathbf{2 0 1 0}$ & $\mathbf{2 0 1 4}$ & MÉDIA \\
\hline PRB & $\mathrm{X}$ & $\mathrm{X}$ & $\mathrm{X}$ & $\mathrm{REF}$ & 0,33 & 0,55 & 0,44 \\
PTdoB & $\mathrm{X}$ & $\mathrm{REF}$ & 0,25 & 0,00 & 0,00 & 0,33 & 0,15 \\
PL & 0,00 & 0,20 & $\mathrm{Z}$ & 0,33 & $\mathrm{X}$ & $\mathrm{X}$ & 0,18 \\
PSL & $\mathrm{X}$ & $\mathrm{REF}$ & 0,00 & 0,00 & 0,00 & 0,33 & 0,08 \\
PP/PPB & REF & 0,00 & 0,50 & 0,00 & 0,42 & 0,67 & 0,32 \\
PFL/DEM & REF & 0,67 & $\mathrm{Z}$ & 0,00 & 0,20 & 0,38 & 0,31 \\
PTN & $\mathrm{X}$ & $\mathrm{REF}$ & $\mathrm{Z}$ & 0,25 & 0,33 & 0,40 & 0,33 \\
PRTB & REF & 0,00 & 0,50 & 0,00 & 0,00 & 0,20 & 0,14 \\
PTB & 0,00 & 0,20 & $\mathrm{Z}$ & 0,27 & 0,40 & 0,00 & 0,17 \\
PRP & $\mathrm{X}$ & $\mathrm{REF}$ & 0,40 & 1,00 & 0,00 & 0,42 & 0,45 \\
PSC & $\mathrm{REF}$ & 0,25 & 0,17 & 0,25 & 0,30 & 0,40 & 0,27 \\
PRN/PTC & REF & 0,33 & 0,17 & 0,33 & 0,18 & 0,38 & 0,28 \\
PSDC & $\mathrm{X}$ & $\mathrm{REF}$ & 0,00 & 0,00 & 0,00 & 0,31 & 0,08 \\
PSD & REF & 0,00 & 0,00 & $X$ & $X$ & $X$ & 0,00 \\
PR & $X$ & $X$ & $X$ & $X$ & $R E F$ & 0,29 & 0,29 \\
PAN & $X$ & REF & 0,00 & 0,00 & $X$ & $X$ & 0,00 \\
PRONA & REF & 0,00 & 0,33 & 0,00 & $X$ & $X$ & 0,11 \\
PGT & $X$ & REF & 0,10 & $X$ & $X$ & $X$ & 0,10 \\
PST & 0,00 & 0,00 & 0,33 & $X$ & $X$ & $X$ & 0,11
\end{tabular}




\begin{tabular}{lccccccc}
\hline \multicolumn{1}{c}{ DIREITA } & $\mathbf{0 , 0 0}$ & $\mathbf{0 , 1 7}$ & $\mathbf{0 , 2 1}$ & $\mathbf{0 , 1 6}$ & $\mathbf{0 , 1 7}$ & $\mathbf{0 , 3 3}$ & $\mathbf{0 , 2 0}$ \\
\hline PMDB & 0,17 & 0,00 & $\mathrm{Z}$ & 0,00 & 0,25 & 0,38 & 0,16 \\
PSDB & 0,10 & 0,57 & $\mathrm{Z}$ & 0,50 & 0,00 & 0,09 & 0,25 \\
\hline \multicolumn{1}{c}{ CENTRO } & $\mathbf{0 , 1 3}$ & $\mathbf{0 , 2 9}$ & $\mathrm{Z}$ & $\mathbf{0 , 2 5}$ & $\mathbf{0 , 1 3}$ & $\mathbf{0 , 2 3}$ & $\mathbf{0 , 2 1}$ \\
\hline PCB & 1,00 & 0,11 & 0,00 & 0,00 & 0,00 & 0,00 & 0,19 \\
PDT & 0,33 & 0,36 & $\mathrm{Z}$ & 0,33 & 0,07 & 0,60 & 0,34 \\
PCdoB & 0,74 & 0,93 & $\mathrm{Z}$ & 0,50 & 0,64 & 0,70 & 0,70 \\
PT & 0,56 & 0,81 & $\mathrm{Z}$ & 0,57 & 0,56 & 0,80 & 0,66 \\
PV & $\mathrm{REF}$ & 0,45 & 0,50 & 0,17 & 0,20 & 0,43 & 0,35 \\
PMN & 0,17 & 0,30 & $\mathrm{Z}$ & 0,50 & 0,25 & 0,14 & 0,27 \\
PHS & $\mathrm{X}$ & $\mathrm{X}$ & $\mathrm{REF}$ & 0,25 & 0,08 & 0,73 & 0,35 \\
PPS & $\mathrm{REF}$ & 0,50 & $\mathrm{Z}$ & 0,20 & 0,30 & 0,43 & 0,36 \\
\hline ESQUERDA & $\mathbf{0 , 5 6}$ & $\mathbf{0 , 5 0}$ & $\mathbf{0 , 2 5}$ & $\mathbf{0 , 3 2}$ & $\mathbf{0 , 2 6}$ & $\mathbf{0 , 4 8}$ & $\mathbf{0 , 4 0}$ \\
\hline
\end{tabular}

Fonte: Elaboração própria (TSE)

* REF= primeira referência de dados; $X=$ inexistência da legenda ou ausência de coligação no período anterior à REF; $Z$ = eleição atípica em que houve um gap na série histórica e o critério $t-2$ foi utilizado para o cálculo da fidelidade aliancista.

A fidelidade aliancista média é maior entre o PSB e os partidos de esquerda, embora seja possível observar resultados relevantes também com partidos de direita. A aliança entre o PSB e o PCdoB se repete, em média, em 70\% das UF's, e entre o partido socialista e o PT em $65 \%$. Os maiores resultados ocorreram em 1998 com $F A=0,93$ com primeiro partido, e $F A=0,81$ com o segundo. É interessante observar esta fidelidade longitudinalmente, pois embora a literatura sinalize para o crescimento de coligações inconsistentes ideologicamente em meados da década de 1990, e se tenha observado anteriormente neste trabalho queda da frequência das alianças do PSB com partidos de esquerda, há uma manutenção das parcerias em determinados estados, contribuindo para que os resultados da fidelidade ainda sejam elevados. Isto significa dizer que, embora a relação entre o PSB e o PT a nível federal tenha sido estremecida (tanto em 2002 com a candidatura de Garotinho e a verticalização das coligações, como em 2014 com o lançamento de Eduardo Campo/Marina Silva à presidência), o que muito provavelmente influenciou na redução da incidência de alianças entre os dois partidos para as eleições executivas estaduais, este impacto é reduzido quando considerado que a maior parte das UF's permaneceram fiéis à parceria.

Entre os partidos de centro, a parceria PSB e PSDB apresentou fidelidade média de $25 \%$, enquanto que com o PMDB o resultado foi $16 \%$. No entanto, constatou-se que estes laços foram mais intensos com este último, especialmente nas duas últimas eleições, embora os melhores percentuais tenham ocorrido na aliança do PSB com o PSDB (0,57 em 1998 e $0,50 \mathrm{em}$ 2006). 
Em relação aos partidos de direita e o PSB, há uma tendência crescente da fidelidade na maioria dos partidos, principalmente depois de 2002. Destacam-se os laços entre o PSB e PP/PPB, PFL/DEM, PTN, PRP e PRB, todos com fidelidade aliancista média superior a 30\%, indicando que há relações de fidelidade entre o PSB e os partidos do outro lado do espectro ideológico. Cabe destacar que o maior percentual ocorreu na aliança com o PP/PPB em 2014, e com o PFL/DEM 1998, ambos com 67\%. A única aliança que não apresentou fidelidade foi entre o PSB e o PSD, apesar de terem sido feitas 19 alianças (ver tabela 1). Por fim, é sabido que houve um movimento geral de pragmatização das coligações, e de crescimento das "coligações inconsistentes", mas observou-se que, mesmo em "coligações esdrúxulas", e quando analisada em pares, há laços de fidelidade entre os partidos nos estados.

\section{Considerações Finais}

$\mathrm{O}$ artigo aqui apresentado pretendeu contribuir para a ampliação da agenda de pesquisa sobre coligações no Brasil, mas com ênfase em um estudo de caso, e, desse modo, investiuse em uma outra direção privilegiando a análise desagregada de dados, com enfoque longitudinal. Observar o comportamento aliancista do PSB desta maneira permitiu compreender as variações de perfis, e suas interações no que diz respeito ao eixo ideológico, além de possibilitar analisar uma outra dimensão, qual seja, a manutenção de vínculos entre os partidos.

Em síntese, foi possível identificar dois perfis distintos de alianças do PSB: um mais ideológico e outro mais aberto a parcerias indiscriminadas. Constatou-se que, de 1990 a 1998, o PSB fez alianças predominantemente com partidos também de esquerda, sobretudo com o PT, PCdoB e PDT. Em 2002, o partido lançou Anthony Garotinho à Presidência, em coligação com o PGT e PTC, e, por conta da vigência da Lei da Verticalização e consequentemente a impossibilidade de fazer parcerias com os adversários desta disputa, aliou-se principalmente com esses dois partidos nas eleições para Governador. Em 2006, período no qual ainda estava em vigor a verticalização, o PSB preferiu não participar de coligações para as eleições executivas nacionais, tendo liberdade para escolher seus parceiros nos Estados, e observou-se a intensificação das alianças com partidos de direita.

Estes achados vão ao encontro do que fora verificado em trabalhos anteriores (Krause e Godoi, 2010; Carreirão e Nascimento, 2010; Miguel e Machado, 2007 e 2010), que, analisando as coligações de maneira agregada, ou em blocos, apontaram para o crescimento de acordos não ideológicos (pragmáticos) em detrimento dos ideológicos. Porém, tais estudos concluíram que não há estabilidade ou padrão nas coligações eleitorais no país, no espaço e no tempo, ou seja, as coligações seriam soluções particulares a cada eleição e 
localidade. Neste ponto, olhando por um outro prisma, ou seja, para a relação bilateral entre os partidos na ação de coligação, o presente artigo chegou a constatações diferentes.

O estudo sobre o PSB sinaliza para uma tendência das alianças se manterem ao longo do tempo. Conforme salientou Soares (1973, p.481-482) ao estudar as coligações na democracia de 1945-1964, não se deve concluir que diferentes eleições representam soluções exclusivamente conjunturais, pois as coligações possuem certas estruturas que se repetem ao longo do tempo, e isto porque as opiniões políticas de um estado não são voláteis, há lealdade e base ideológica na política. Em relação à manutenção de vínculos com os partidos ao longo do tempo, o PSB foi mais fiel em suas alianças também com os partidos de esquerda (fidelidade aliancista média de 0,40 ), do que com os de direita e centro (fidelidade média de 0,20 e 0,21 , respectivamente). No entanto, por mais que este partido tenha flexibilizado suas alianças a partir de 2006, os resultados obtidos mostram que, ainda assim, permaneceu mais fiel aos parceiros de esquerda, já que a fidelidade aliancista encontrada com estes supera as demais em 2006, 2010 e 2014. Ou seja, o PSB diversificou suas alianças, mas manteve laços de lealdade mais intensos com partidos de esquerda.

Apesar das limitações intrínsecas a construção de indicadores dedicados a captar o comportamento de objetos dinâmicos, a análise desagregada das coligações contribui para a observação de possíveis lógicas de ação delineada por cada um dos partidos e de que forma estas estratégias são nacionalizadas, ou particulares a cada unidade federativa.

Porém, testes com outros partidos são necessários para avaliar o comportamento deste indicador, e verificar se a ideia da fidelidade aliancista sobrevive. Soma-se a isso a necessidade de cruzar estas informações com os resultados eleitorais, o que permitiria avaliar se esta "estratégia" partidária seria maximizadora. Por fim, é necessário refletir sobre a classificação dos partidos no que se refere à ideologia, pois, se as alianças fossem utilizadas como um critério, o PSB possivelmente não seria alocado à esquerda do espectro ideológico.

\section{Referências Bibliográficas}

CADERNOS ADENAUER. Rio de Janeiro: Fundação Konrad Adenauer, no 2, junho 2013. Título do Fascículo: Candidatos, partidos e coligações nas eleições municipais de 2012.

CARREIRÃO, Y. S. Ideologia e partidos políticos: um estudo sobre coligações em Santa Catarina. Opinião Pública, vol.12, nº 12, pp.136-163, 2006. 
CARREIRÃO, Y. S.; NASCIMENTO, F. P. As coligações nas eleições para o Senado brasileiro (1990/2006). In KRAUSE, DANTAS E MIGUEL, Partidos e coligações eleitorais no Brasil. Rio de Janeiro: Fundação Konrad Adenauer; São Paulo: Fundação Editora da Unesp, 2010.

DANTAS, H. Coligações em eleições majoritárias municipais: a lógica do alinhamento dos partidos políticos brasileiros nas disputas de 2000 e 2004. Tese (Doutorado) - Faculdade de Filosofia, Letras e Ciências Humanas, Universidade de São Paulo, São Paulo, 2007.

DOWNS, A. An Economic Theory of Democracy. New York: Harper, 1957.

FERREIRA, D. P.; BATISTA, C. M.; STABILE, M. A evolução do sistema partidário brasileiro: número de partidos e votação no plano subnacional 1982-2006. In: Opinião Pública, vol.14, no 2, Campinas, nov.2008.

FLEISCHER, D. Os partidos políticos. In: CINTRA e AVELAR, Sistema político brasileiro: uma introdução. São Paulo: Unesp, 2007.

. Articulação de coligações no Brasil - antes e depois da verticalização (1994 e 1998 versus 2002 e 2006): impactos sobre os partidos. In: KRAUSE, DANTAS E MIGUEL, Partidos e coligações eleitorais no Brasil. Rio de Janeiro: Fundação Konrad Adenauer; São Paulo: Fundação Editora da Unesp, 2010.

GUSTIN, Miracy; VIEIRA, Margarida. Semeando a Democracia: A trajetória do socialismo democrático no Brasil. Contagem; Editora Palesa,1995.

KRAUSE, S.; SCHMITT, R. Partidos e coligações eleitorais no Brasil. Rio de Janeiro: Fundação Konrad Adenauer; São Paulo: Fundação Editora da Unesp, 2005.

KRAUSE, S.; GODOI, P.P. Coligações eleitorais para os executivos estaduais (1986-2006). In KRAUSE, DANTAS E MIGUEL. Partidos e coligações eleitorais no Brasil. Rio de Janeiro: Fundação Konrad Adenauer; São Paulo: Fundação Editora da Unesp, 2010.

KRAUSE, S; DANTAS, H.; MIGUEL, L.F. Coligações partidárias na nova democracia brasileira. Rio de Janeiro: Fundação Konrad Adenauer; São Paulo: Fundação Editora da Unesp, 2010.

LAMOUNIER, B., MENEGUELLO, R. Partidos políticos e consolidação democrática: o caso brasileiro. São Paulo: Brasiliense, 1986. 
LIMA JR., O. B. de. Os partidos políticos brasileiros: a experiência federal e regional (19451964). Rio de Janeiro: Graal, 1983.

MACHADO, C. M. M.; MIGUEL, L. F. Coerência, coesão e consistência: uma proposta de tipologia para coligações municipais. In: $6^{0}$ Encontro da ABCP, Campinas: Unicamp, 2008.

MIRANDA, G. L. Coligações Eleitorais: tendências e racionalidades nas eleições federais e majoritárias estaduais (1990-2010). In: Revista de Sociologia e Política, v.21, no 47, set.2013, pp.69-90.

NEUMANN, J. V.; MORGENSTERN, O. Theory of games and economic behavior. Princeton: Princeton University Press, 1944.

NICOLAU, J. Partidos na República de 1946: velhas teses, novos dados. In: Dados, Rio de Janeiro, n.1, 2004.

OLIVEIRA, I. R. de. Notas sobre o comportamento das coligações eleitorais no Brasil (19501962). In: Dados, Rio de Janeiro, n.10, 1973.

PANEBIANCO, A. Modelos de partido: Organização e Poder nos Partidos. Martins Fontes. São Paulo, 2005.

MELO, Carlos Ranulfo; CAMARA, Rafael. Estrutura da competição pela Presidência e consolidação do sistema partidário no Brasil. Dados, Rio de Janeiro, v. 55, n. 1, p. 71-117, 2012.

MIGUEL, L. F.; MACHADO, C. Um equilíbrio delicado: a dinâmica das coligações do PT em eleições municipais (2000 e 2004). In: Dados, v. 50, n. 4, p. 757-793, Rio de Janeiro, 2007.

. De partido de esquerda a partido do governo. O PT e suas coligações para prefeito (2000 a 2008). In: KRAUSE, S.; DANTAS, H.; MIGUEL, L. F. Coligações Partidárias na Nova Democracia Brasileira. Rio de Janeiro: Fundação Konrad Adenauer e Editora UNESP, 2010.

SANTOS, W. G. Crise e Castigo: partidos e generais na política brasileira. São Paulo: Vértice; Rio de Janeiro: IUPERJ, 1987.

SCHMITT, R. Coligações eleitorais e sistema partidário no Brasil. Tese (Doutorado em Ciência Política). Rio de Janeiro: Iuperj, 1999.

SOARES, G. A. D. Alianças e Coligações Eleitorais: notas para uma teoria. In: Revista Brasileira de Estudos Políticos, n.17, p.95-124, 1964. 
. Alianzas Electorales em el Brasil. In: Revista Mexicana de Sociología, Vol. 35, No. 3, Jul.-Sep., 1973a, pp. 457-492. Disponível em: http://www.jstor.org/stable/3539608. Acesso em: 05-11-2015.

Sociedade e Política no Brasil. São Paulo: Difusão Européia do Livro, 1973b.

. A democracia interrompida. Rio de Janeiro: Editora FGV, 2001. 
Anexo 1 - As coligações do PSB para Governador do Estado (1990-2014)*

\begin{tabular}{|c|c|c|c|c|c|c|c|}
\hline UF & 1990 & 1994 & 1998 & 2002 & 2006 & 2010 & 2014 \\
\hline $\mathrm{AC}$ & $\begin{array}{l}\text { não apresenta } \\
\text { candidato }\end{array}$ & $\begin{array}{l}\text { PT, PCdoB,PSB, } \\
\text { PV,PSTU }\end{array}$ & $\begin{array}{l}\text { PDT,PT,PSL,PPS, } \\
\text { PSB,PSDB,PTdo } \\
\text { B,PCdoB,PV, } \\
\text { PMN,PL,PTB }\end{array}$ & $\begin{array}{l}\text { não apresenta } \\
\text { candidato }\end{array}$ & $\begin{array}{l}\text { PP,PT,PL,PRTB,P } \\
\text { MN, PSB,PCdoB }\end{array}$ & $\begin{array}{l}\text { PRB,PP,PDT,PT, } \\
\text { PTB, } \\
\text { PTN,PR,PSDC,P } \\
\text { HS,PTC,PSB, } \\
\text { PV,PRP,PCdoB }\end{array}$ & $\begin{array}{l}\text { PDT,PRB,PT,PSL } \\
\text {,PTN, } \\
\text { PSDC,PHS,PSB,P } \\
\text { RP,PEN,PPL,PCd } \\
\text { oB,PROS,PTB }\end{array}$ \\
\hline AL & $\begin{array}{l}\text { PT, PCB, PSB, } \\
\text { PCdoB }\end{array}$ & $\begin{array}{l}\text { PMDB, PTB, } \\
\text { PSB,PL, PCdoB, } \\
\text { PSD }\end{array}$ & $\begin{array}{l}\text { PDT,PTdoB,PCdo } \\
B, P T, \\
P R O N A, P R P, P V, \\
P T N, P P S, P S N, P S \\
B, P M N, P S T\end{array}$ & $\begin{array}{l}P S B, P S T, P A N, P H \\
S, P S C, \\
P T C, P S D C, P V, P \\
R O N A, \\
P R P, P G T, P T d o B, \\
P S L\end{array}$ & $\begin{array}{l}\text { não apresenta } \\
\text { candidato }\end{array}$ & $\begin{array}{l}\text { PP,PSC,PPS,DE } \\
\text { M,PSB, PSDB }\end{array}$ & $\begin{array}{l}\text { PPS,PP,PSDC,PR } \\
\text { P,PR, } \\
\text { PSL,PSB,DEM,SD }\end{array}$ \\
\hline $\mathrm{AM}$ & $\begin{array}{l}\text { PSDB, PDT, PT, } \\
\text { PSB, PCdoB, PCB }\end{array}$ & $\begin{array}{l}\text { PL, PCdoB, PPS, } \\
\text { PSB, PMN, } \\
\text { PRONA }\end{array}$ & $\begin{array}{l}\text { PPB,PCdoB,PSB,P } \\
\text { MN, } \\
\text { PPS,PSL,PT,PDT }\end{array}$ & $P S B, P T C, P P B, P V$ & $\begin{array}{l}\text { não apresenta } \\
\text { candidato }\end{array}$ & $\begin{array}{l}\text { PDT,PT,PSL,PR,P } \\
\text { SDC, PSB,PTdoB }\end{array}$ & PSB \\
\hline AP & $\begin{array}{l}\text { PCB, PSB, PSDB, } \\
\text { PCdoB, PT }\end{array}$ & $\begin{array}{l}\text { PSB, PT, PDT, } \\
P C d o B, P V\end{array}$ & $\begin{array}{l}P T, P S B, P A N, P P S \\
, P V, P C d o B, P R P\end{array}$ & $P S B, P R P$ & PSB & $P T, P S B$ & $\begin{array}{l}P S B, P T, P S O L, P C d \\
o B\end{array}$ \\
\hline BA & PCdoB,PSB,PCB & $\begin{array}{l}\text { PSDB, PPS, PV, } \\
\text { PSB, PCdoB,PT }\end{array}$ & $\begin{array}{l}\text { PDT,PRTB,PPS,PS } \\
\text { N,PSB,PRP,PSDB, } \\
\text { PV,PMN }\end{array}$ & $P G T, P S B$ & $\begin{array}{l}\text { PT,PMDB,PCdoB } \\
\text {,PSB, } \\
\text { PPS,PV,PTB,PM } \\
\text { N,PRB }\end{array}$ & $\begin{array}{l}\text { PRB,PP,PDT,PT, } \\
\text { PSL,PHS,PSB,PC } \\
\text { doB }\end{array}$ & $P S B, P S L, P P L$ \\
\hline
\end{tabular}




\begin{tabular}{|c|c|c|c|c|c|c|c|}
\hline $\mathrm{CE}$ & $\begin{array}{l}\text { PT,PCB,PSB,PCdo } \\
\text { B }\end{array}$ & $\begin{array}{l}\text { PT,PSB , PPS , PC } \\
\text { doB }\end{array}$ & $\begin{array}{l}\text { PDT,PT,PSB,PCd } \\
\text { oB,PV, PCB }\end{array}$ & $\begin{array}{l}\text { PSB,PSDC,PSC,P } \\
\text { SL,PGT, } \\
\text { PTdoB,PHS,PAN, } \\
\text { PRTB }\end{array}$ & $\begin{array}{l}P S B, P T, P C d o B, P \\
M D B, \\
P R B, P P, P H S, P M \\
N, P V\end{array}$ & $\begin{array}{l}P R B, P D T, P T, P M \\
D B, P S C, P S B, P C d \\
o B\end{array}$ & PSB \\
\hline $\mathrm{DF}$ & $\begin{array}{l}\text { PDT,PCB,PSB,PS } \\
\text { DB,PEB,PCdoB }\end{array}$ & $\begin{array}{l}\text { PT, PSB, PCdoB, } \\
\text { PPS, PSTU }\end{array}$ & $\begin{array}{l}\text { PDT,PV,PSB,PCd } \\
\text { oB,PMN,PT,PCB, } \\
\text { PSN }\end{array}$ & $P H S, P S B, P V$ & $\begin{array}{l}\text { PT,PV,PCdoB,PSB } \\
\text {,PRTB,PRB }\end{array}$ & $\begin{array}{l}\text { PRB,PDT,PT,PTB } \\
\text {,PMDB,PPS,PHS, } \\
\text { PTC,PSB,PRP, } \\
\text { PCdoB }\end{array}$ & $P S B, S D, P D T, P S D$ \\
\hline ES & $\begin{array}{l}\text { PDT,PSB,PTB,PC } \\
\text { doB }\end{array}$ & PT, PSB, PCdoB & $\begin{array}{l}P T, P T N, P M N, P C d \\
o B, P S B, P S N\end{array}$ & $\begin{array}{l}\text { PSB,PSD,PSC,PR } \\
\text { ONA,PTdoB,PV, } \\
\text { PAN,PSL,PHS }\end{array}$ & $\begin{array}{l}\text { não apresenta } \\
\text { candidato }\end{array}$ & $\begin{array}{l}\text { PRB,PP,PDT,PT, } \\
\text { PMDB,PTN,PSC, } \\
\text { PR,PSDC,PHS,PT } \\
\text { C,PSB,PV,PRP,P } \\
\text { CdoB,PTdoB }\end{array}$ & $\begin{array}{l}\text { PSB,PSDC,PSL,PP } \\
\text { PRTB, } \\
\text { PTdoB,PPS,PR,PS } \\
\text { C,PSD, } \\
\text { PTC,PCdoB,PV,P } \\
\text { HS,PTN, } \\
\text { PPL,PMN,PRB,PT } \\
B\end{array}$ \\
\hline GO & PT, PSB & $\begin{array}{l}\text { não apresenta } \\
\text { candidato }\end{array}$ & $\begin{array}{l}\text { PMDB,PTdoB,PR } \\
\text { P,PSD, } \\
\text { PSB,PRN,PRTB,P } \\
\text { TN,PSC,PL,PAN, } \\
\text { PPS,PST,PSL }\end{array}$ & PGT,PTC,PSB & $P S B, P T, P C d o B$ & $\begin{array}{l}\text { PP,PDT,PTN,PSC, } \\
\text { PR, } \\
\text { PSDC,PSB,PV,PR } \\
\text { P }\end{array}$ & $P S B, P S C, P R P$ \\
\hline MA & $\begin{array}{l}\text { PDT, PT, } \\
\text { PSB,PCdoB }\end{array}$ & $\begin{array}{l}\text { PPR, PSB, PSDB, } \\
\text { PRN, PRONA }\end{array}$ & $\begin{array}{l}\text { PPB,PTdoB,PDT, } \\
\text { PRN, } \\
\text { PSB,PSDB,PMN }\end{array}$ & $\begin{array}{l}\text { não apresenta } \\
\text { candidato }\end{array}$ & $\begin{array}{l}P R B, P T, P M N, P S B \\
, P C d o B\end{array}$ & PPS,PSB,PCdoB & $\begin{array}{l}\text { PP,SD,PROS,PS } \\
\text { DB,PPS, } \\
\text { PCdoB,PSB,PDT, } \\
\text { PTC }\end{array}$ \\
\hline
\end{tabular}




\begin{tabular}{|c|c|c|c|c|c|c|c|}
\hline MG & $\begin{array}{l}\text { PT,PCB,PSB,PCdo } \\
\text { B }\end{array}$ & $\begin{array}{l}\text { PSDB, PTB, PL, } \\
\text { PT, PDT, PCdoB, } \\
\text { PSB, PMN, PPS, } \\
\text { PSD, PMDB, PPS }\end{array}$ & $\begin{array}{l}\text { PDT,PCdoB,PV,P } \\
\text { T,PCB, PSB }\end{array}$ & PSB & $\begin{array}{l}\text { PP,PTB,PSC,PL,P } \\
\text { PS,PFL,PAN,PHS } \\
\text {,PSB,PSDB }\end{array}$ & $\begin{array}{l}\text { PP,PDT,PTB,PSL, } \\
\text { PSC,PR,PPS,DE } \\
\text { M,PSDC,PMN, } \\
\text { PSB,PSDB }\end{array}$ & $P S B, P P L, P R T B$ \\
\hline MS & $\begin{array}{l}\text { PT,PCB,PSB,PCdo } \\
\text { B }\end{array}$ & $\begin{array}{l}\text { PMDB, PSDB, } \\
\text { PSB, PCdoB, PL, } \\
\text { PV, PSD }\end{array}$ & $\begin{array}{l}\text { não apresenta } \\
\text { candidato }\end{array}$ & $\begin{array}{l}P S B, P R O N A, P R P, \\
P G T\end{array}$ & $\begin{array}{l}\text { PT,PSB,PTB,PCdo } \\
\text { B,PP, } \\
\text { PTN,PHS,PRP }\end{array}$ & $\begin{array}{l}\text { PRB,PTB,PTC,PT } \\
\text { N,PPS, } \\
\text { DEM,PRTB,PHS, } \\
\text { PMN,PR,PSB,PS } \\
\text { DB,PTdoB,PMD } \\
\text { B }\end{array}$ & $\begin{array}{l}\text { PMDB,PSB,PTdo } \\
\text { B,PSC, } \\
\text { PHS,PRB,PRTB,P } \\
\text { TN,PEN }\end{array}$ \\
\hline MT & $\begin{array}{l}\text { PDT,PT,PCB,PSB, } \\
\text { PCdoB }\end{array}$ & $\begin{array}{l}\text { PDT, PT, PSDB, } \\
\text { PMDB, PSB, } \\
\text { PCdoB, PPS, } \\
\text { PSC, PV, PMN }\end{array}$ & $\begin{array}{l}\text { PMN,PSB,PSDB, } \\
\text { PV }\end{array}$ & PHS,PTC,PSB & $\begin{array}{l}\text { PP,PTB,PMDB,P } \\
\text { TN,PL, } \\
\text { PPS,PFL,PAN,PR } \\
\text { TB, } \\
\text { PMN,PTC,PSB,P } \\
\text { V }\end{array}$ & $P D T, P P S, P S B, P V$ & $\begin{array}{l}\text { PDT,PP,DEM,PS } \\
\text { DB,PSB, } \\
\text { PPS,PV,PTB,PSD } \\
\text { C,PSC, } \\
\text { PRP,PSL,PRB }\end{array}$ \\
\hline PA & $\begin{array}{l}\text { PDT, PT, PCB, } \\
\text { PSB, PSDB, } \\
\text { PCdoB }\end{array}$ & $\begin{array}{l}\text { PSDB, PFL, PDT, } \\
\text { PTB, PSB, PPS, } \\
\text { PCB }\end{array}$ & $\begin{array}{l}P T, P C B, P S B, P C d o \\
B\end{array}$ & $\begin{array}{l}P S L, P S C, P H S, P S B \\
, P G T, P T C\end{array}$ & $\begin{array}{l}\text { PRB,PT,PTN,PSB } \\
\text {,PCdoB }\end{array}$ & $\begin{array}{l}\text { PRB,PP,PDT,PT,P } \\
\text { TB, } \\
\text { PTN,PSC,PR,PHS, } \\
\text { PTC, } \\
\text { PSB,PV,PCdoB,PT } \\
\text { doB }\end{array}$ & $\begin{array}{l}\text { PSDB,PSD,PSB,P } \\
\text { RB,PSC,PTB,PPS, } \\
\text { PEN,PMN,PTC, } \\
\text { PP,PSDC,PTdoB, } \\
\text { SD,PRP }\end{array}$ \\
\hline PB & $\begin{array}{l}\text { PT, PCB, PSB, } \\
\text { PCdoB }\end{array}$ & $\begin{array}{l}\text { PT,PCdoB, } \\
\text { PSB,PV,PSTU }\end{array}$ & $P T, P V, P C d o B, P S B$ & $\begin{array}{l}\text { não apresenta } \\
\text { candidato }\end{array}$ & $\begin{array}{l}\text { PRB,PT,PMDB,PS } \\
\text { B, PCdoB }\end{array}$ & $\begin{array}{l}P D T, P T N, P P S, D E \\
M, P T C, P S B, P V, P \\
R P, P S D B\end{array}$ & $\begin{array}{l}P S B, P T, P D T, D E \\
M, P R T B, P R P, P V, \\
P S L, P C d o B, P H S, \\
P P L\end{array}$ \\
\hline
\end{tabular}




\begin{tabular}{|c|c|c|c|c|c|c|c|}
\hline PE & $\begin{array}{l}\text { PDT,PMDB,PCB, } \\
\text { PMN, } \\
\text { PSDB,PS,PSB,PCd } \\
\text { oB }\end{array}$ & $\begin{array}{l}\text { PSB,PT,PDT,PCd } \\
\text { oB,PPS,PV,PMN }\end{array}$ & $\begin{array}{l}P D T, P T, P R T B, P C \\
B, P T B \\
P G T, P S B, P C d o B, P \\
S D, P M N\end{array}$ & $\begin{array}{l}\text { PSB,PRTB,PTdoB, } \\
\text { PRP }\end{array}$ & $\begin{array}{l}P P, P D T, P S C, P L, \\
P S B\end{array}$ & $\begin{array}{l}P R B, P P, P D T, P T, \\
P T B, P S L, P S C, P R, \\
P S D C, P H S, P T C, \\
P S B, P R P, P C d o B, \\
P T d o B\end{array}$ & $\begin{array}{l}\text { PMDB,PSB,PTC, } \\
P P, P R P, P V, P T N, \\
P R, P S D, P P S, S D, \\
P S D B, P P L, D E M, \\
P H S, \\
P E N, P S D C, P R O S \\
\text { PRTB, } \\
P C d o B, P S L\end{array}$ \\
\hline PI & $\begin{array}{l}\text { PDT, PT, PSB, } \\
\text { PCdoB }\end{array}$ & PT, PSB & PT,PSC,PSDB,PSB & PSB & $\begin{array}{l}\text { PT,PSB,PTB,PCd } \\
\text { oB,PL }\end{array}$ & $\begin{array}{l}P R B, P T, P M D B, P \\
T N, P R, \\
P S B, P R P, P C d o B\end{array}$ & $\begin{array}{l}\text { PMDB,PSDB,PSB, } \\
\text { PRB, } \\
\text { PDT,PSL,PTN,PP } \\
\text { S,DEM, } \\
\text { PSDC,PMN,PTC, } \\
\text { PSD, } \\
\text { PCdoB,PTdoB,PV } \\
\text {,PEN }\end{array}$ \\
\hline PR & PT, PSB & $\begin{array}{l}\text { PDT,PTB, } \\
\text { PSDB,PPR, } \\
\text { PFL,PPS,PSB,PV }\end{array}$ & $\begin{array}{l}\text { PPB,PST,PSC,PP } \\
\text { S,PRN, } \\
\text { PSD,PTdoB,PRP, } \\
\text { PSB,PL,PFL,PTN, } \\
\text { PTB,PSL }\end{array}$ & PSB,PGT & $\begin{array}{l}\text { PP,PDT,PTB,PTN, } \\
\text { PMN, } \\
\text { PTC,PSB,PRONA, } \\
\text { PTdoB }\end{array}$ & $\begin{array}{l}\text { PRB,PTB,PSL,PT } \\
\text { N,PPS, } \\
\text { PP,DEM,PSDC,P } \\
\text { HS,PMN,PTC,PS } \\
\text { B,PRP,PSDB }\end{array}$ & $\begin{array}{l}\text { PSDB,PROS,DE } \\
\text { M,PSB, } \\
\text { PSD,PTB,PP,PPS, } \\
\text { PSC,PR,SD,PSL, } \\
\text { PSDC,PMN,PHS, } \\
\text { PEN,PTdoB }\end{array}$ \\
\hline RJ & PT, PSB & $\begin{array}{l}\text { PT,PSB,PCdoB,PV } \\
\text {,PRTB,PTC }\end{array}$ & $\begin{array}{l}\text { PDT,PCB,PT,PCd } \\
\text { oB,PSB }\end{array}$ & $\begin{array}{l}P S B, P P B, P S T, P T \\
C, P S C, \\
P R P, P S D, P G T\end{array}$ & PT,PSB,PCdoB & $\begin{array}{l}\text { PDT,PT,PTB,PM } \\
\text { DB,PSL, } \\
\text { PTN,PP,PSC,PSD } \\
\text { C,PRTB,PHS,PM }\end{array}$ & PT,PV,PSB,PCdoB \\
\hline
\end{tabular}




\begin{tabular}{|c|c|c|c|c|c|c|c|}
\hline & & & & & & $\begin{array}{l}\text { N,PTC,PSB,PRP, } \\
\text { PCdoB }\end{array}$ & \\
\hline $\mathrm{RN}$ & PT,PSB,PCdoB & $P S B, P F L$ & $\begin{array}{l}\text { PTB,PSL,PSB,PSD } \\
\text { B,PV, PFL,PL }\end{array}$ & PSB,PGT,PST & $\begin{array}{l}\text { PSB,PTB,PT,PL,P } \\
\text { PS,PHS,PMN,PC } \\
\text { doB,PTdoB }\end{array}$ & $P T, P T B, P P S, P S B$ & $\begin{array}{l}\text { PMDB,PR,PSB,PR } \\
\text { OS,SD, } \\
\text { PDT,PSC,PTB,PP } \\
\text { S,PHS, } \\
\text { PSDB,PSDC,PRB, } \\
\text { PTN,PV,PMN,PR } \\
\text { P }\end{array}$ \\
\hline $\mathrm{RO}$ & $\begin{array}{l}\text { PMDB,PDC,PL,P } \\
\text { MN,PSB }\end{array}$ & $\begin{array}{l}\text { PMDB, PSDB, } \\
\text { PSB }\end{array}$ & $\begin{array}{l}\text { não apresenta } \\
\text { candidato }\end{array}$ & PSB & $P D T, P T B, P L, P S B$ & PT,PSB & $\begin{array}{l}\text { PCdoB,PMDB,P } \\
\text { DT,PSB, } \\
\text { PRTB,PTN,PTB,P } \\
\text { SL,PRP }\end{array}$ \\
\hline RR & $\begin{array}{l}\text { PSDB,PDT,PSB,P } \\
\text { ST, PCdoB }\end{array}$ & $\begin{array}{l}\text { não apresenta } \\
\text { candidato }\end{array}$ & $\begin{array}{l}\text { não apresenta } \\
\text { candidato }\end{array}$ & $\begin{array}{l}\text { não apresenta } \\
\text { candidato }\end{array}$ & $\begin{array}{l}\text { PMDB,PPS,PSB,P } \\
\text { MN,PT,PRB,PCdo } \\
\text { B,PSC,PTC,PV }\end{array}$ & $\begin{array}{l}\text { PP,PT,PTB,PSC,P } \\
\text { HS,PTC,PSB }\end{array}$ & $\begin{array}{l}\text { PSB,PMDB,PSDB, } \\
P R, P R B, P S D, P S L, \\
P P S, P S C, P R T B, \\
S D, P M N, P S D C, P \\
T d o B, P H S, P P L, P T \\
N, P E N, P R P, P R O S\end{array}$ \\
\hline RS & $\begin{array}{l}\text { não apresenta } \\
\text { candidato }\end{array}$ & $\begin{array}{l}\text { PT,PSB,PPS,PCdo } \\
\text { B,PV, PSTU }\end{array}$ & $\begin{array}{l}\text { PT,PCdoB,PSB,P } \\
\text { CB }\end{array}$ & PSB & PSB & $\begin{array}{l}\text { PT,PR,PSB,PCdo } \\
\text { B }\end{array}$ & $\begin{array}{l}\text { PMDB,PSD,PPS, } \\
\text { PSB,PHS,PTdoB, } \\
\text { PSL,PSDC }\end{array}$ \\
\hline SC & $\begin{array}{l}\text { não apresenta } \\
\text { candidato }\end{array}$ & $\begin{array}{l}\text { PDT,PT,PPS,PSB, } \\
\text { PSDB, PCdoB }\end{array}$ & $\begin{array}{l}\text { PDT,PCdoB,PSB, } \\
\text { PMN,PSN,PPS,P } \\
\text { CB,PT }\end{array}$ & $P S B, P S D$ & $P T B, P S B$ & $\begin{array}{l}\text { PRB,PT,PR,PSDC, } \\
\text { PRTB,PHS,PSB,P } \\
\text { CdoB }\end{array}$ & $\begin{array}{l}\text { PP,PSL,PTN,PPS, } \\
\text { PRTB,PHS,PTC,P } \\
\text { SB,PSDB,PEN,PT } \\
\text { doB,SD }\end{array}$ \\
\hline
\end{tabular}




\begin{tabular}{|c|c|c|c|c|c|c|c|}
\hline SE & PT, PCdoB, PSB & $\begin{array}{l}\text { PDT, PMN, PP, } \\
\text { PT, PSB, PCdoB }\end{array}$ & $\begin{array}{l}P D T, P T, P S B, P C d o \\
B, P C B\end{array}$ & $\begin{array}{l}\text { não apresenta } \\
\text { candidato }\end{array}$ & $\begin{array}{l}\text { PT,PTB,PMDB,P } \\
\text { L,PSB, PCdoB }\end{array}$ & $\begin{array}{l}\text { PRB,PDT,PT,PM } \\
\text { DB,PSL,PSC,PR, } \\
\text { PTC,PSB,PCdoB }\end{array}$ & $\begin{array}{l}\text { PT,PSD,PCdoB,P } \\
\text { RTB, } \\
\text { PDT,PRP,PROS, } \\
\text { PSDC, } \\
\text { PMDB,PSB,PRB }\end{array}$ \\
\hline $\mathrm{SP}$ & $\begin{array}{l}\text { PCdoB, PSB, PCB, } \\
\text { PT }\end{array}$ & $\begin{array}{l}\text { PT,PSB,PPS,PCdo } \\
\text { B,PSTU,PCB,PM } \\
\text { N }\end{array}$ & $\begin{array}{l}\text { PDT,PSB,PTN,PS } \\
\text { N,PAN }\end{array}$ & PSB & PSB & $P S L, P S B$ & $\begin{array}{l}\text { PSDB,DEM,PEN, } \\
\text { PTC,SD,PTN,PP } \\
\text { S,PMN,PTdoB, } \\
\text { PRB,PSB,PSC,PS } \\
\text { DC,PSL }\end{array}$ \\
\hline $\mathrm{TO}$ & $\begin{array}{l}\text { não apresenta } \\
\text { candidato }\end{array}$ & $\begin{array}{l}\text { PMDB, PSDB, } \\
\text { PDT, PL, PSC, } \\
\text { PSD, PRN, PSB, } \\
\text { PCdoB }\end{array}$ & $\begin{array}{l}\text { PDT,PTdoB,PRP, } \\
\text { PV,PSB,PGT,PR } \\
\text { TB,PSDC,PL,PSC } \\
\text {,PTN,PSDB,PFL, } \\
\text { PPB,PST,PTB }\end{array}$ & $\begin{array}{l}\text { PSB, PSC, } P H S, P G \\
T\end{array}$ & $\begin{array}{l}\text { PP,PTB,PSC,PL,P } \\
\text { SB,PV, } \\
\text { PSDB,PTdoB }\end{array}$ & $\begin{array}{l}\text { PP,PDT,PT,PMDB } \\
\text {,PSL, } \\
\text { PPS,PSDC,PHS,P } \\
\text { SB,PRP,PCdoB }\end{array}$ & $\begin{array}{l}\text { PRB,PP,PDT,PTB, } \\
\text { PSL, } \\
\text { PSC,PR,PPS,DEM } \\
\text {,PRTB, } \\
\text { PHS,PTC,PSB,PR } \\
\text { P,PSDB,PEN,SD }\end{array}$ \\
\hline
\end{tabular}

Fonte: Elaboração própria (TSE)

* Negrito = sucesso eleitoral; Itálico = cabeça de chapa; Negrito=cabeça de chapa com sucesso eleitoral 